\title{
1 Hydrogen isotope response to changing salinity and rainfall in Australian mangroves
}

$9{ }^{a}$ School of Oceanography, University of Washington, Box 355315, Seattle, WA 98195, USA 10 snladd@uw.edu,jsachs@uw.edu 
Hydrogen isotope ratios $\left({ }^{2} \mathrm{H} /{ }^{1} \mathrm{H}, \delta^{2} \mathrm{H}\right)$ of leaf waxes covary with those in precipitation and

35 are therefore a useful paleohydrologic proxy. Mangroves are an exception to this relationship

36 because their $\delta^{2} \mathrm{H}$ values are also influenced by salinity. The mechanisms underlying this

37 response were investigated by measuring leaf lipid $\delta^{2} \mathrm{H}$ and leaf and xylem water $\delta^{2} \mathrm{H}$ and $\delta^{18} \mathrm{O}$

38 values from three mangrove species over 9.5 months in a subtropical Australian estuary. Net

$39{ }^{2} \mathrm{H} /{ }^{1} \mathrm{H}$ fractionation between surface water and leaf lipids decreased by $0.5-1.0 \% \mathrm{ppt}^{-1}$ for $n$ -

40 alkanes and $0.4-0.8 \% \mathrm{ppt}^{-1}$ for isoprenoids. Xylem water was ${ }^{2} \mathrm{H}$ depleted relative to surface

41 water, reflecting ${ }^{2} \mathrm{H}$ discrimination of 4-10\% during water uptake at all salinities and

42 opportunistic uptake of freshwater at high salinity. However, leaf water ${ }^{2} \mathrm{H}$ enrichment relative to

43 estuary water was insensitive to salinity and identical for all species. Therefore variations in leaf

44 and xylem water $\delta^{2} \mathrm{H}$ values cannot explain the salinity-dependent ${ }^{2} \mathrm{H}$ depletion in leaf lipids, nor

45 the $30 \%$ range in leaf lipid $\delta^{2} \mathrm{H}$ values among species. Biochemical changes in direct response to

46 salt stress, such as increased compatible solute production or preferential use of stored

47 carbohydrates, and/or the timing of lipid production and subsequent turnover rates, are more

48 likely causes.

\section{INTRODUCTION}

51 Hydrogen isotopes of plant leaf waxes are a valuable source of information about the

52 water cycle, and $\delta^{2} \mathrm{H}_{\mathrm{Wax}}\left(\delta^{2} \mathrm{H}=\left({ }^{2} \mathrm{H} /{ }^{1} \mathrm{H}_{\text {Sample }}\right) /\left({ }^{2} \mathrm{H} /{ }^{1} \mathrm{H}_{\text {VSMOW }}\right)-1\right)$ values are increasingly used as a

53 paleoclimate proxy (Sachse et al., 2012; Gao et al., 2014). Over large environmental gradients,

54 the primary cause of variability in $\delta^{2} \mathrm{H}_{\text {Wax }}$ values are the $\delta^{2} \mathrm{H}$ values of local precipitation (Huang

55 et al., 2004; Sachse et al., 2004; Hou et al., 2008; Polissar \& Freeman, 2010; Sachse et al., 
56 2012; Tipple \& Pagani, 2013), which is directly related to environmental variables such as

57 temperature, rainfall rate, and moisture source (Dansgaard, 1964; Craig \& Gordon, 1965; Gat, 58 1996).

59 However, changes in $\delta^{2} H_{\text {Precipitation }}$ are not the only cause of variability in $\delta^{2} H_{\text {Wax }}$ (Sachse et al., 2012; Gao et al., 2014). Other environmental variables have demonstrated influence on

$61 \delta^{2} \mathrm{H}_{\mathrm{Wax}}$ in some settings. Factors such as plant type (Luo et al., 2006; Smith \& Freeman, 2006;

62 Hou et al., 2007; Feakins \& Sessions, 2010a), relative humidity (Feakins \& Sessions, 2010b;

63 Douglas et al., 2012; Kahmen et al., 2013a; Kahmen et al., 2013b; Tipple et al., 2014), and light

64 levels (Luo \& Yang, 2008; Yang et al., 2009) can affect the offset between $\delta^{2} \mathrm{H}_{\text {Wax }}$ and $\delta^{2} \mathrm{H}_{\text {Water, }}$,

65 which is defined by the fractionation factor $\alpha_{\text {Lipid-Water }}\left(\alpha_{\text {Lipid-Water }}=\left(\delta^{2} \mathrm{H}_{\text {Lipid }}+1000\right) /\left(\delta^{2} \mathrm{H}_{\text {Water }}+\right.\right.$

66 1000)). On tropical and subtropical coastlines where mangroves are present, salinity is another

67 important variable that can affect $\alpha_{\text {Lipid-Water. }}$ Mangroves contribute $\sim 30 \%$ of total organic

68 material to coastal marine sediments in the tropics and subtropics (Alongi and Mukhopadhyay,

692014 ). It is therefore essential to understand this effect in order to accurately apply the $\delta^{2} \mathrm{H}_{\text {Lipid }}$

70 proxy in low-latitude coastal sediments.

71 Increased salinity is correlated with apparent isotope fractionation in mangroves growing

72 along spatial salinity gradients at a single point in time (Ladd \& Sachs, 2012; Ladd \& Sachs, in

73 review). In the Brisbane River, $\alpha_{\text {Lipid-Water }}$ decreased by $1.5 \pm 0.3 \% \mathrm{PSU}^{-1}$ for both $n \mathrm{C}_{31}$ - and

$74 \quad n \mathrm{C}_{33}$-alkanes produced by Avicennia marina (gray mangroves) growing along a salinity gradient

75 of 6-35 PSU (Ladd \& Sachs, 2012). For the pentacyclic tripterpenoid taraxerol produced by

76 Rhizophora spp. (red mangroves) growing along three Micronesian estuaries and four marine

77 lakes in Palau, $\alpha_{\text {Lipid-Water }}$ decreased by $0.9 \pm 0.2 \% 0 \mathrm{PSU}^{-1}$. For $n$-alkanes produced by the same

78 plants, $\alpha_{\text {Lipid-Water }}$ decreased by $1.0 \pm 0.3 \% \mathrm{PSU}^{-1}$ (Ladd \& Sachs, in review). 
The main goal of the present study was to investigate how changes in apparent isotope

80 fractionation manifest themselves throughout the year by studying mangroves at a single location

81 with highly seasonal and episodic precipitation. Similar time series of temperate plants have

82 produced conflicting results, with some indicating that leaf wax isotopes reflect the

83 environmental conditions during leaf flush (Sachse et al., 2010; Tipple et al., 2013), and some

84 suggesting leaf wax regeneration and isotopic shifts throughout the growth season (Sachse et al.,

85 2009; Gao \& Huang, 2013). More relevant for evergreen tropical plants, such as the mangroves

86 studied here, was a recent study of evergreen broadleaf trees from California (Quercus agrifolia)

87 (Sachse et al., 2015). The results of this study indicated that leaf waxes were formed and

88 regenerated over the first three months of the leaf's existence, and subsequently were isotopically

89 stable (Sachse et al., 2015). Leaf lipids from mangroves, which produce new leaves throughout

90 the year (Wium-Andersen\& Christensen, 1978; Duke et al., 1984; Coupland et al., 2005) may

91 thus represent aggregate annual conditions.

92 Another major goal of the present study was to better understand the mechanism that

93 results in greater net discrimination against ${ }^{2} \mathrm{H}$ during the synthesis of mangrove lipids at high

94 salinity. Previous hypotheses for increased fractionation at high salinity are (1) increased

95 discrimination against ${ }^{2} \mathrm{H}$ during water uptake by roots, (2) increased production of compatible

96 solutes, resulting in changes in the NADPH pool used for lipid synthesis, and (3) salt on the leaf

97 surface, which increases the relative humidity along the leaf boundary layer and decreases the

98 vapor pressure difference between the interior and exterior of the leaf (Ladd \& Sachs, 2012).

99 This third mechanism should be more pronounced for mangroves that secrete salt, such as

100 Avicennia and Aegicerus, than for mangroves that lack this function, such as Rhizophora. 
Analyzing the isotopic composition of xylem water $\left(\delta^{2} \mathrm{H}_{\mathrm{XW}}\right)$ and leaf water $\left(\delta^{2} \mathrm{H}_{\mathrm{LW}}\right)$ is an

102 effective method to investigate causes of net fractionation during lipid synthesis (Feakins \&

103 Sessions, 2010a; Romero \& Feakins, 2011; Kahmen et al., 2013b; Tipple et al., 2013; Gao et al.,

104 2014). Here we included weekly measurements of these values from adjacent salt-secreting and

105 non-secreting trees over a 9.5-month period to test the relative likelihood of each of the three

106 hypotheses summarized above.

107

\section{METHODS}

\section{Study site and sample collection}

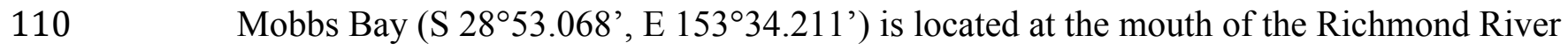

111 in South Ballina, New South Wales, Australia (Figure 1). South Ballina has a humid subtropical

112 climate, with mean maximum temperatures ranging from $19.9^{\circ} \mathrm{C}$ in July to $28.2^{\circ} \mathrm{C}$ in January

113 (Australian Bureau of Meteorology). Mean annual rainfall is $1768.6 \mathrm{~mm} / \mathrm{year}$, with a wet season

114 from January to June and a dry season from July to December. On average, March is the wettest

115 month, with an average of $214.3 \mathrm{~mm} / \mathrm{month}$, and September is the driest month with 61.3

$116 \mathrm{~mm} / \mathrm{month}$ (Australian Bureau of Meteorology).

117 The study period began on October 1, 2012 and lasted until July 17, 2013. During weekly

118 site visits, surface water salinity (1 cm depth) was measured with a refractometer (VeeGee

119 Scientific, Kirkland, WA) with accuracy of \pm 1 ppt. Salinity varied from 36 ppt on October 24,

1202012 to $1 \mathrm{ppt}$ on March $6^{\text {th }}, 2013.4 \mathrm{~mL}$ of water was collected from $1 \mathrm{~cm}$ below the surface for

121 isotopic analysis.

122 One Avicennia marina individual and one Rhizophora stylosa individual growing

123 adjacent to one another on the fringe of the mangrove swamp were selected for study. In March 
1242013 , one Aegiceras corniculatum individual was added to the study. The roots of all three trees

125 were fully flooded at high tide. Each week, two sun-exposed branches were collected from each

126 tree. One or two leaves from each branch were stored in an $11 \mathrm{~mL}$ glass screw cap vial for leaf

127 water analysis. The remaining leaves from each branch were stored in Whirlpak plastic bags for

128 lipid analysis. An $\sim 5 \mathrm{~cm}$ length of well-suberized stem on each branch was stored in an $11 \mathrm{~mL}$

129 glass screw cap vial for xylem water analysis. All samples were stored in a cooler with ice and

130 transferred to a $-20^{\circ} \mathrm{C}$ freezer, where they remained prior to analysis.

131 Rainwater samples were collected regularly throughout the study period in East Ballina,

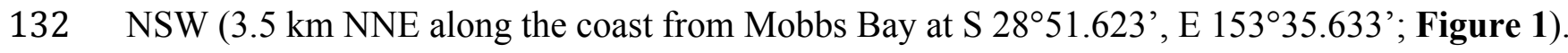

$1334 \mathrm{~mL}$ of rainwater falling on the rooftop of a single story dwelling ( $\sim 3-4 \mathrm{~m}$ high) and flowing to

134 ground level through a downspout was collected once or twice per rain event and stored in a

135 glass screw cap vial sealed with electrical tape.

137 Leaf and xylem water extraction

138 Leaf and xylem water samples were cryogenically extracted on a vacuum line in the

139 Agricultural Sciences Institute at ETH-Zurich, following methods modified from those of West

140 et al. (2006). Samples were heated to $80^{\circ} \mathrm{C}$, while attached to a glass U-tube that was submerged

141 in liquid Nitrogen. The sealed line was kept at a pressure below $60 \mathrm{mTorr}$ for at least two hours.

142 After this time, the U-tubes were removed from the liquid $\mathrm{N}_{2}$, sealed, and the collected water

143 was allowed to thaw. The water was then filtered through a $0.45 \mu \mathrm{m}$ PTFE filter to remove any

144 particulate material and transferred to $2 \mathrm{~mL}$ screw cap vials, which were sealed with Parafilm

145 until analysis. 


\section{Water isotope measurements}

148 Leaf and xylem water samples were analyzed by a Thermal Conversion Elemental

149 Analyzer (TC/EA) coupled to a Delta V Isotope Ratio Mass Spectrometer (IRMS; Thermo

150 Scientific, Waltham, MA) in the Sustainable Land Use Group in the Botany Department of the

151 University of Basel, Switzerland. Each sample and standard was injected six times in sequence.

152 The first three injections of each sample were discarded in order to avoid memory effects.

153 Thermo Isodat 3.0 software normalized raw isotopic ratios to the VSMOW (Vienna Standard

154 Mean Ocean Water) scale using pulses of reference gas before and after the sample injection.

155 Additionally, two in-house water standards of known isotopic composition were analyzed after

156 every six samples throughout each sequence. The slope and intercept of the linear regression

157 between the measured and known $\delta$ values of these standards was used to further normalize

158 sample $\delta^{2} \mathrm{H}$ and $\delta^{18} \mathrm{O}$ values and to correct for any instrumental drift throughout the course of the

159 sequence. An additional laboratory standard was analyzed after every 12 samples. This standard

160 was not used for any of the isotopic corrections, but was used to assess instrument performance

161 over time and the accuracy of the isotope corrections. Average absolute offset from the known

162 value of this standard was $1.0 \%$ for $\delta^{2} \mathrm{H}$ measurements and $0.2 \%$ for $\delta^{18} \mathrm{O}$ measurements.

163 Average precision of triplicate sample injections was $0.9 \%$ for $\delta^{2} \mathrm{H}$ measurements and $0.2 \%$ for

$164 \delta^{18} \mathrm{O}$ measurements.

165 Surface water and rainwater $\delta^{2} \mathrm{H}$ and $\delta^{18} \mathrm{O}$ values were measured by a Picarro Cavity

166 Ring Down Spectroscopy (CRDS) L2130i Water Isotope Analyzer at the University of

167 Washington in Seattle. Measurements were normalized to the VSMOW scale using three

168 laboratory standards of known isotopic composition. The three standards were analyzed between

169 every six samples throughout the run. All samples and standards were injected six times, and the 
170 first three measurements were discarded in order to avoid memory effects. Average precision of

171 triplicate analyses was $0.2 \%$ for $\delta^{2} \mathrm{H}$ measurements and $0.05 \%$ for $\delta^{18} \mathrm{O}$ measurements.

173 Lipid extraction and purification

174 Four intact whole leaves from each week (2 from each branch sampled) were selected for

175 analysis and treated as a single sample. Leaves were rinsed with DI water to remove debris, then

176 cut into $\sim 0.5 \mathrm{~cm}$ pieces using solvent-washed scissors prior to freeze-drying. Dry leaves were

177 ground with a solvent-cleaned mortar and pestle, and lipids from $\sim 0.5 \mathrm{~g}$ of dry leaf were

178 extracted using accelerated solvent extraction (ASE-200, Dionex Corp., Sunnyvale, CA, USA)

179 with 9:1 Dichloromethane:Methanol (DCM:MeOH) at $100{ }^{\circ} \mathrm{C}$ and 1500 psi for $3 \times 5$ min static

180 cycles. The resulting total lipid extract (TLE) was evaporated to dryness under a stream of $\mathrm{N}_{2}$.

181 An aliquot of the TLE ( $\sim 10 \mathrm{mg})$ was purified using silica gel column chromatography.

182 The stationary phase was $1 \mathrm{~g}$ of Si gel (5\% deactivated with water). Hydrocarbons were eluted

183 with $8 \mathrm{~mL}$ hexane (Hex), aldehydes and ketones with $6 \mathrm{~mL}$ 1:1 Hex:DCM, sterols, alcohols and

184 triterpenols with $8 \mathrm{~mL}$ 4:1 Hexane:Ethyl Acetate, and remaining compounds with $4 \mathrm{~mL} \mathrm{MeOH}$.

185 The alcohol fraction was acetylated at $70{ }^{\circ} \mathrm{C}$ for 30 minutes with $25 \mu \mathrm{L}$ of acetic

186 anhydride of known $\delta^{2} \mathrm{H}$ composition in $25 \mu \mathrm{L}$ of pyridine. The alcohol fraction of $R$. stylos $a$

187 leaves of all species was dominated by taraxerol, with relatively small amounts of $\beta$-sitosterol, $\beta$ -

188 amyrin, and $n$-alkanols. Lupeol was the most abundant compound in the alcohol fraction of $A$.

189 marina leaves, which also contained significant amounts of $\alpha$-amyrin, $\beta$-amyrin, $\beta$-sitosterol, and

190 stigmasterol. Although they were not the most abundant alcohols, $\beta$-sitosterol and stigmasterol

191 were the best resolved compounds by gas chromatography (GC), and were thus targeted for

192 isotopic analyses. Stigmastanol was the most abundant compound in the alcohol fraction of $A$. 
193 corniculatum. Lipids in the alcohol fraction were quantified by Gas Chromatography - Mass

194 Spectrometry (GC-MS) using an Agilent (Santa Clara, CA, USA) 6890N gas chromatograph

195 equipped with an Agilent 7683 autosampler, a split-splitless injector operated in splitless mode

196 and an Agilent VF-17ms capillary column (60 m X $0.32 \mathrm{~mm} \mathrm{X} 0.25 \mu \mathrm{m})$ interfaced to an Agilent

1975975 quadrupole mass selective detector. The oven temperature was increased from $110^{\circ} \mathrm{C}$ to

$198320^{\circ} \mathrm{C}$ at $4{ }^{\circ} \mathrm{C} / \mathrm{min}$, then held at $320^{\circ} \mathrm{C}$ for 10 minutes. Quantification of target compounds was

199 performed by comparing integrated peak areas with a known amount of $5 \alpha$-cholestane, added to

200 the sample just prior to GC-MS analysis.

201 The hydrocarbon fraction of leaves of all species was dominated by odd-numbered $n$ -

202 alkanes, with chain lengths ranging from $\mathrm{C}_{27}-\mathrm{C}_{33}$. In $R$. stylosa and A. corniculatum leaves, $n \mathrm{C}_{29}$

203 was the most abundant $n$-alkane, followed by $n \mathrm{C}_{31}$. In $A$. marina leaves $n \mathrm{C}_{31}$ and $n \mathrm{C}_{33}$ were the

204 most abundant alkanes. The $n$-alkanes were quantified with a GC instrument equipped with

205 flame ionization detection (GC-FID). An Agilent 6890N gas chromatograph equipped with an

206 Agilent 7683 autosampler, programmable temperature vaporization inlet (PTV) operated in

207 splitless mode, and an Agilent DB-5ms column (60 m X $0.32 \mathrm{~mm} \mathrm{X} 0.25 \mu \mathrm{m})$ was used with $\mathrm{He}$

208 as carrier gas $(2.4 \mathrm{~mL} / \mathrm{min})$. The oven temperature was increased from 60 to $150{ }^{\circ} \mathrm{C}$ at 15

$209{ }^{\circ} \mathrm{C} / \mathrm{min}$, then at $6{ }^{\circ} \mathrm{C} / \mathrm{min}$ to $320^{\circ} \mathrm{C}$ (held $28 \mathrm{~min}$ ). Quantification of $n$-alkanes was performed by

210 comparing integrated peak areas with a known amount of $n \mathrm{C}_{37}$-alkane, added to the sample just

211 prior to GC-FID analysis.

212 These quantifications were used to determine an appropriate amount of solvent in which

213 to dissolve the sample so that it would produce a peak of $\sim 20$ Volt*sec $\left(V^{*} \mathrm{~s}\right)$ when analyzed by

214 Gas Chromatrography - Isotope Ratio Mass Spectrometry (GC-IRMS). 


\section{Lipid $\delta^{2} H$ analyses}

The $\delta^{2} \mathrm{H}$ values of individual lipids were measured by GC-IRMS on a Thermo DELTA V

218 PLUS system (Thermo Scientific, Waltham, MA, USA). The GC (Trace Ultra, Thermo) was

219 equipped with a split-splitless injector operated in splitless mode at $320^{\circ} \mathrm{C}$, a TRIPLUS

220 autosampler (Thermo Scientific), and a VF-17ms capillary column (60 m X $0.25 \mathrm{~mm} \mathrm{X} 0.25 \mu \mathrm{m}$,

221 Agilent). For taraxerol and stigmastanol analyses, the $\mathrm{GC}$ was heated from $120^{\circ} \mathrm{C}$ to $260{ }^{\circ} \mathrm{C}$ at

$22220{ }^{\circ} \mathrm{C} / \mathrm{min}$, then at $1{ }^{\circ} \mathrm{C} / \min$ to $300{ }^{\circ} \mathrm{C}$, at $20^{\circ} \mathrm{C} / \min$ to $325^{\circ} \mathrm{C}$ and then held at $325^{\circ} \mathrm{C}$ for 20

$223 \mathrm{~min}$. For $\beta$-sitosterol and stigmansterol from A. marina the $\mathrm{GC}$ was heated from $120{ }^{\circ} \mathrm{C}$ to 260

$224{ }^{\circ} \mathrm{C}$ at $20{ }^{\circ} \mathrm{C} / \mathrm{min}$, then at $1{ }^{\circ} \mathrm{C} / \mathrm{min}$ to $300{ }^{\circ} \mathrm{C}$, at $20{ }^{\circ} \mathrm{C} / \mathrm{min}$ to $325^{\circ} \mathrm{C}$ and then held at $325^{\circ} \mathrm{C}$ for

$22540 \mathrm{~min}$. For $n$-alkane analyses, the $\mathrm{GC}$ was heated from $120{ }^{\circ} \mathrm{C}$ to $250{ }^{\circ} \mathrm{C}$ at $20^{\circ} \mathrm{C} / \mathrm{min}$, then at 6

$226{ }^{\circ} \mathrm{C} / \mathrm{min}$ to $325^{\circ} \mathrm{C}$ and then held at $325^{\circ} \mathrm{C}$ for $12 \mathrm{~min}$. Helium was used as the carrier gas at a

227 constant flow of $1.1 \mathrm{~mL} / \mathrm{min}$. Compounds were pyrolyzed in a ceramic reactor at $1400{ }^{\circ} \mathrm{C} .1 \mu \mathrm{L}$

228 of sample was injected along with $0.5 \mu \mathrm{L}$ of a mix of $n$-alkanes of known isotopic composition

229 (A. Schimmelmann, Indiana University, Bloomington, Indiana). For isoprenoid analyses, this

230 mix included $n \mathrm{C}_{26^{-}}, n \mathrm{C}_{28^{-}}, n \mathrm{C}_{32^{-}}, n \mathrm{C}_{34^{-}}$and $n \mathrm{C}_{41^{-}}$-alkanes. For $n$-alkane analyses, the co-injection

231 standards were $n \mathrm{C}_{21}$ and $n \mathrm{C}_{23}$. At the beginning and the end of the sequence, as well as after

232 every 4-6 sample injections, a mixture of additional $n$-alkane standards of known isotopic

233 composition was analyzed with the co-injection standards, in place of a sample. For isoprenoid

234 sequences, this external standard was $n \mathrm{C}_{38}$-alkane, which elutes within 1 minute of taraxerol

235 under these $\mathrm{GC}$ conditions. For $n$-alkane sequences, $n \mathrm{C}_{28^{-}}, n \mathrm{C}_{32^{-}}$and $n \mathrm{C}_{34}$-alkanes were used as

236 external standards.

237 Thermo ISODAT software V.2.5 was used to control instrumentation and calculate $\delta^{2} \mathrm{H}$

238 values. The slope and intercept of the relationship between measured and known $\delta^{2} \mathrm{H}$ values of 
239 the $n$-alkane standards was used to correct lipid $\delta^{2} \mathrm{H}$ values for instrument bias. Offsets between

240 corrected and known standard $\delta^{2} \mathrm{H}$ values were used to further correct for drift, retention time,

241 and peak area for each sequence. Each sample was measured in triplicate. Reported analytical

242 uncertainties are the standard deviation of triplicate sample analyses. $\mathrm{The}_{3}{ }^{+}$factor was

243 determined each day using pulses of a reference gas of varying heights and averaged $1.7 \%$.

245 RESULTS

246 Relationship between salinity and $\delta^{2} \mathbf{H} / \delta^{18} \mathrm{O}$ values of different water pools

247 There was an $84 \%$ range in $\delta^{2} H_{\text {Precipitaion }}$ values throughout the study period, from $17.8 \pm$

$2480.2 \%$ to $-67.3 \pm 0.2 \%$ (Table S1). Values of $\delta^{18} \mathrm{O}_{\text {Precipitation }}$ varied by $\sim 11 \%$ o throughout the study

249 period, from $0.21 \pm 0.05 \%$ to $-10.97 \pm 0.05 \%$ (Table S1). Lighter rainwater isotopes

250 corresponded to periods of heavier rainfall in the summer and autumn, with heavier rainwater

251 isotopes predominant in the drier spring. Surface water isotopes in Mobbs Bay varied between -

$25229 \pm 0.2 \%$ and $6 \pm 0.2 \%$ for $\delta^{2} \mathrm{H}$ and $-5.15 \pm 0.05 \%$ and $0.48 \pm 0.05 \%$ for $\delta^{18} \mathrm{O}$, changing in

253 concert with rain events, with lower values during wet episodes and higher values during dry

254 periods (Figure 2a-c).

255 Salinity and surface water isotopes $\left(\delta^{2} \mathrm{H}_{\mathrm{SW}}\right.$ and $\left.\delta^{18} \mathrm{O}_{\mathrm{SW}}\right)$ at the study site were well

256 correlated throughout the year (Figure 3; $\mathrm{R}^{2}=0.76$ for $\delta^{2} \mathrm{H} ; \mathrm{R}^{2}=0.85$ for $\left.\delta^{18} \mathrm{O}\right)$. A $1 \mathrm{ppt}$

257 increase in salinity resulted in increases of $0.77 \pm 0.07 \%$ for $\delta^{2} \mathrm{H}_{\mathrm{SW}}$ and $0.14 \pm 0.01 \%$ for $\delta^{18} \mathrm{O}_{\mathrm{SW}}$

258 (Figure 3).

259 Xylem water isotopes $\left(\delta^{2} \mathrm{H}_{\mathrm{Xw}}\right.$ and $\left.\delta^{18} \mathrm{O}_{\mathrm{Xw}}\right)$ in $R$. stylos $a$ and $A$. marina were positively

260 correlated with salinity as well, but with significantly shallower slopes than the surface water

261 (Figure 3). For R. stylosa, $\delta^{2} \mathrm{H}_{\mathrm{Xw}}$ increased by $0.45 \pm 0.09 \% \mathrm{ppt}^{-1}\left(\mathrm{R}^{2}=0.39\right)$ (Figure 3d) and 
$262 \delta^{18} \mathrm{O}_{\mathrm{XW}}$ increased by $0.08 \pm 0.02 \% \mathrm{ppt}^{-1}\left(\mathrm{R}^{2}=0.40\right)$ (Figure 3a). For $A$. marina, a 1 ppt increase

263 in salinity was associated with a $0.43 \pm 0.08 \%$ increase in $\delta^{2} \mathrm{H}_{\mathrm{XW}}\left(\mathrm{R}^{2}=0.44\right)$ (Figure 3e) and

264 with a $0.07 \pm 0.02 \%$ increase in $\delta^{18} \mathrm{O}_{\mathrm{XW}}\left(\mathrm{R}^{2}=0.36\right)$ (Figure 3b). Xylem water isotopes and

265 salinity were not correlated in A. corniculatum, which was only sampled for the last 14 weeks of

266 the study period ( $\mathrm{p}=0.79$ for $\delta^{2} \mathrm{H}_{\mathrm{XW}}$ and 0.82 for $\left.\delta^{18} \mathrm{O}_{\mathrm{XW}}\right)$ (Figures 3c and 3f).

267 The apparent fractionation factors between surface water and xylem water $\left(\alpha^{2}{ }_{\mathrm{XW}}{ }_{\mathrm{SW}}=\right.$

$268\left(\delta^{2} \mathrm{H}_{\mathrm{XW}}+1000\right) /\left(\delta^{2} \mathrm{H}_{\mathrm{SW}}+1000\right)$ and $\left.\alpha^{18} \mathrm{XW-SW}=\left(\delta^{18} \mathrm{O}_{\mathrm{XW}}+1000\right) /\left(\delta^{18} \mathrm{O}_{\mathrm{SW}}+1000\right)\right)$ were

269 negatively correlated with salinity for $R$. stylosa and A. marina (Figure 4). For R. stylosa, $\alpha^{2} \mathrm{xw}$ -

270 sw decreased by $0.3 \pm 0.1 \% \mathrm{ppt}^{-1}\left(\mathrm{R}^{2}=0.20\right)$ (Figure 4a) and $\alpha^{18} \mathrm{XW-Sw}$ decreased by $0.06 \pm$

$271 \quad 0.02 \% \mathrm{ppt}^{-1}\left(\mathrm{R}^{2}=0.23\right)\left(\right.$ Figure 4d). For A. marina, $\alpha^{2}$ Xw-Sw decreased by $0.3 \pm 0.1 \%$ o $\mathrm{ppt}^{-1}\left(\mathrm{R}^{2}\right.$

$272=0.28)$ (Figure 4b) and $\alpha^{18}$ XW-sw decreased by $0.06 \pm 0.02 \%$ ppt ${ }^{-1}\left(\mathrm{R}^{2}=0.23\right)$ (Figure 4e).

273 Salinity was not significantly correlated with either $\alpha^{2}$ XW-sw or $\alpha^{18}$ XW-Sw in $A$. corniculatum (p=

2740.14 for $\alpha^{2}$ XW-SW and 0.12 for $\alpha^{18}$ XW-SW) (Figures $4 \mathbf{c}$ and $4 \mathbf{f}$ ).

275 Leaf water isotopes $\left(\delta^{2} \mathrm{H}_{\mathrm{LW}}\right.$ and $\left.\delta^{18} \mathrm{O}_{\mathrm{LW}}\right)$ were positively correlated with salinity in $R$.

276 stylosa and A. marina, with slopes that were significantly steeper than the relationship between

277 salinity and xylem water, but statistically indistinguishable from the relationship between salinity

278 and surface water isotopes (Figure 3). For $R$. stylosa, a 1 ppt increase in salinity was associated

279 with a $0.9 \pm 0.2 \%$ increase in $\delta^{2} \mathrm{H}_{\mathrm{LW}}\left(\mathrm{R}^{2}=0.35\right)$ (Figure 3d) and with a $0.22 \pm 0.07 \%$ increase

280 in $\delta^{18} \mathrm{O}_{\mathrm{LW}}\left(\mathrm{R}^{2}=0.25\right)$ (Figure 3a). For $A$. marina, a $1 \mathrm{ppt}$ increase in salinity was associated with

281 a $0.7 \pm 0.2 \%$ increase in $\delta^{2} \mathrm{H}_{\mathrm{LW}}\left(\mathrm{R}^{2}=0.28\right)$ (Figure 3e) and with a $0.16 \pm 0.06 \%$ increase in

$282 \delta^{18} \mathrm{O}_{\mathrm{LW}}\left(\mathrm{R}^{2}=0.17\right)$ (Figure 3b). Leaf water isotopes in A. corniculatum were not correlated with

283 salinity $\left(\mathrm{p}=0.73\right.$ for $\delta^{2} \mathrm{H}_{\mathrm{LW}}$ and 0.74 for $\left.\delta^{18} \mathrm{O}_{\mathrm{LW}}\right)$ (Figures 3c and 3f). 
No significant correlations existed between salinity and the net hydrogen isotope

285 fractionation between surface water and leaf water, $\alpha^{2} \mathrm{Lw}$-sw, in any species, (Figures 5a-c)

286 Likewise, no significant correlations existed between salinity and the evaporative enrichment of

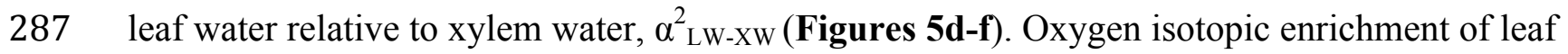

288 water relative to surface water and to xylem water was similarly uncorrelated with salinity and is

289 not shown.

291 Temporal variability of lipid $\boldsymbol{\delta}^{2} \mathbf{H}$

292 Leaf lipid $\delta^{2} \mathrm{H}$ values varied throughout the year, and differed significantly between $R$.

293 stylosa and the other two species (Figures $2 \mathbf{d}$ and 2e). For R. stylosa, $n \mathrm{C}_{29}$-alkane $\delta^{2} \mathrm{H}$ values

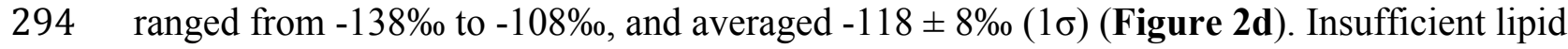

295 quantities precluded analysis in some samples, but from the 25 weeks where $\delta^{2} \mathrm{H}$ values of the

$296 n \mathrm{C}_{31}$-alkane were measured, they varied from $-141 \%$ to $-115 \%$ and averaged $-128 \pm 7 \%$ o

297 (Figure 2d). The pentacyclic triterpenoid measured from this plant, taraxerol, had $\delta^{2} \mathrm{H}$ values

298 that varied from $-192 \%$ to $-154 \%$, with an average value of $-173 \pm 10 \%$ (Figure $2 e$ ).

299 For A. marina, $n \mathrm{C}_{31}$-alkane $\delta^{2} \mathrm{H}$ values varied from $-169 \%$ to $-143 \%$ and averaged -154

$300 \pm 6 \%$ (Figure 2d). The $\delta^{2} \mathrm{H}$ values of $n \mathrm{C}_{33}$-alkanes from this plant ranged from - $180 \%$ to $-142 \% 0$

301 with an average value of $-158 \pm 10 \%$. $\beta$-sitosterol $\delta^{2} \mathrm{H}$ values varied from $-218 \%$ o to $-185 \%$,

302 averaging $-200 \pm 7 \%$ (Figure 2e). For stigmasterol, $\delta^{2} \mathrm{H}$ values ranged from $-224 \%$ to $-195 \%$,

303 with an average of $-207 \pm 7 \%$ (Figure 2e).

304 Finally, $n \mathrm{C}_{29}$-alkane $\delta^{2} \mathrm{H}$ values from $A$. corniculatum, which were only measured from

305 March $28^{\text {th }}$ onwards, varied from $-169 \%$ to $-146 \%$, and averaged $-163 \pm 8 \%$ (Figure $2 d$ ). The

$306 n \mathrm{C}_{31}$-alkane $\delta^{2} \mathrm{H}$ values from this plant, which were measured for only 11 weeks, ranged from - 
$307168 \%$ to $-148 \%$, averaging $-162 \pm 5 \%$ (Figure 2d). Stigmastanol $\delta^{2} \mathrm{H}$ values from $A$.

308 corniculatum ranged from $-242 \%$ to $-218 \%$, with an average of $-230 \pm 7 \%$ (Figure 2e).

309 The apparent fractionation factor between surface water and leaf lipids $\left(\alpha_{\text {Lipid-Sw }}\right)$ was

310 negatively correlated with salinity for all lipids from A. marina and $R$. stylosa, and for $n \mathrm{C}_{29}$ -

311 alkane from $A$. corniculatum (Figure 6). There was no significant correlation for $A$.

312 corniculatum $n \mathrm{C}_{31}$-alkane $(\mathrm{p}=0.21)$ or stigmastanol $(\mathrm{p}=0.39)$ (Figure 6). Significant

313 differences in the y-intercept of these linear relationships existed $(\mathrm{p}<0.0001)$, but the slopes

314 were not significantly different $(\mathrm{p}=0.10)$.

315

316 DISCUSSION

317 Fractionation during water uptake and transpiration by mangroves

318 Mangroves and other woody halophytes discriminate against ${ }^{2} \mathrm{H}$ by as much as $11 \%$

319 during water uptake by roots (Lin \& Sternberg, 1993; Ellsworth \& Williams, 2007).

320 Corresponding discrimination has not been observed against ${ }^{18} \mathrm{O}$, permitting the use of $\delta^{18} \mathrm{O}_{\mathrm{Xw}}$ to

321 determine mangroves' environmental water source (Lin \& Sternberg, 1994; Ewe et al., 2007;

322 Lambs et al., 2008; Wei et al., 2013; Santini et al., 2015). Assuming the $\delta^{18} \mathrm{O}$ values of xylem

323 water from mangroves in Mobbs Bay represent the isotopic composition of the their water

324 source, surface $(-1 \mathrm{~cm})$ water was not the only water used by these trees, since $\delta^{18} \mathrm{O}_{\mathrm{Xw}}$ values

325 were usually $2-3 \%$ depleted in ${ }^{18} \mathrm{O}$ relative to surface water at salinity $>\sim 20$ ppt (Figures $\mathbf{2 b}, \mathbf{3 a}$ -

326 3c). Other potential water sources for the mangroves in Mobbs Bay include groundwater (Ewe et

327 al., 2007; Lambs et al., 2008), freshwater runoff during rain events (Wei et al., 2013; Santini et

328 al., 2015; Reef et al., 2015), and foliar uptake of rain or dew (reviewed in Reef \& Lovelock,

329 2015). Foliar water uptake is an important water sources for some plants (Burgess \& Dawson, 
2004; Johnson \& Smith, 2008; Eller et al., 2013). Thus far only indirect evidence, such as

331 reverse xylem flow during rainfall events (De Groote, 2013) and at night (Rada et al., 1989; Hao

332 et al., 2009) has suggested that foliar water uptake might occur in mangroves (Reef \& Lovelock,

333 2015).

334 It seems more likely that mangroves are able to selectively take up sporadically available

335 freshwater through their roots during rain events. When A. marina seedlings were grown in split

336 plots where each half of the plant's roots were exposed to different water treatments, the

337 mangroves used three times as much water from the low salinity ( $5 \mathrm{ppt})$ half than from the

338 seawater salinity side (35 ppt) (Reef et al., 2015). This change in water uptake rate was observed

339 within hours of decreasing salinity from one root chamber from 35 to $5 \mathrm{ppt}$, and demonstrates

340 that mangroves may be able to increase water uptake through only one portion of their roots in

341 response to freshwater runoff (Reef et al., 2015).

342 Salinity and $\alpha^{18}$ XW-Sw are negatively correlated, implying that the studied mangroves

343 relied less on surface water as the salinity of that water increased (Figures $4 d$ and $4 \mathbf{e})$. The

344 selective use of fresher water sources at high salinities has been documented previously (Ewe et

345 al., 2007; Lambs et al., 2008; Wei et al., 2013; Ladd \& Sachs, in review) and is consistent with

346 increasingly negative $\delta^{18} \mathrm{O}_{\mathrm{XW}}$ values as salinity increased in Mobbs Bay mangroves.

$347{ }^{2} \mathrm{H}$ depletion of xylem water from $R$. stylosa and A. marina relative to surface water was

348 observed at all salinities, even when $\delta^{18} \mathrm{O}_{\mathrm{XW}}$ values were not depleted relative to surface water

349 (Figures 2, 3d-3f). Furthermore, $\delta^{2} \mathrm{H}_{\mathrm{XW}}$ values were lower than those predicted from $\delta^{18} \mathrm{O}_{\mathrm{XW}}$,

350 assuming a constant relationship between the two isotopes in both xylem water and local surface

351 water (Figure 7). Discrimination against ${ }^{2} \mathrm{H}$ during water uptake by halophyte roots has been

352 reported previously and likely caused low $\delta^{2} \mathrm{H}_{\mathrm{XW}}$ values in Mobbs Bay mangroves relative to 
$353 \delta^{2} \mathrm{H}_{\mathrm{sw}}$ (Lin \& Sternberg, 1993; Ellsworth \& Williams, 2007; Ladd \& Sachs, in review). The

354 magnitude of this effect can be determined from the relationships between $\alpha_{\mathrm{xw}-\mathrm{sw}}$ and salinity

355 for each isotope. For both A. marina and R. stylosa, the y-intercept of the regression between

$356 \quad \alpha^{18} \mathrm{XW-Sw}$ and salinity is 1.000 (Figure $4 \mathbf{d}$ and $4 \mathbf{e}$ ), indicating that when surface water is fresh, it

357 is the primary water source for the mangroves. The y-intercepts for the linear regression between

$358 \alpha^{2}$ XW-sw and salinity are $0.993 \pm 0.003$ for $R$. stylos $a$ and $0.994 \pm 0.002$ for $A$. marina (Figures

359 4a and $4 \mathbf{b}) .{ }^{2} \mathrm{H}$ discrimination during water uptake is thus $7 \pm 3 \%$ by $R$. stylos $a$ and $6 \pm 2 \%$ for

360 A. marina. These values compare favorably with published reports of $2-11 \%{ }^{2} \mathrm{H}$ depletion in

361 the xylem water of mangroves and other woody halophytes (Lin \& Sternberg, 1993; Ellsworth \&

362 Williams, 2007).

363 While the xylem water isotope values are informative about the water pools accessed by

364 mangroves growing in Mobbs Bay, and suggest that mangroves discriminate against ${ }^{2} \mathrm{H}$ during

365 water uptake, they cannot explain the inverse relationship between salinity and $\alpha_{\text {Lipid-sw }}$ observed

366 here and elsewhere (Figure 6; Ladd \& Sachs, 2012; Ladd \& Sachs, in review). This is because

367 the leaf water isotopes track surface water isotopes much better than xylem water isotopes

368 (Figures 3, 5), and leaf water is the source of at least $96 \%$ of the hydrogen for leaf lipids

369 synthesized by dicots (Kahmen et al., 2013b). There is no salinity dependence for either $\alpha_{\text {LW-sw }}^{2}$

370 or $\alpha^{18}{ }_{\text {LW-Sw }}$ in any of the three species studied (Figures 5a-c). This result suggests that

371 environmental variables such as relative humidity and the isotopic composition of ambient water

372 vapor have a more significant impact on leaf water isotopes in mangroves than the isotopic

373 composition of xylem water.

374

375 Differences in biosynthetic fractionation among different species of mangroves 
In contrast to the nearly identical xylem water and leaf water isotopes among the three

377 species, there were significant differences in the $\delta^{2} H_{\text {Lipid }}$ values (Figure 2). In particular, the $\delta^{2} \mathrm{H}$

378 values of $n \mathrm{C}_{31}$-alkane, the one compound that was produced in sufficient abundance by all three

379 species, was consistently enriched in $R$. stylosa relative to the other two species by $\sim 25-30 \%$ o

380 (Figure 2d). This interspecies variability highlights a potential complication of using $n$-alkane

$381 \delta^{2} \mathrm{H}$ values to reconstruct past hydroclimate, as a large shift in sedimentary $n \mathrm{C}_{31}$-alkane $\delta^{2} \mathrm{H}$

382 values in a setting like Mobbs Bay could reflect a change in the dominant mangrove species

383 rather than being driven solely by hydrological conditions.

384 Significant variation in interspecies $\delta^{2} \mathrm{H}$ values was also observed in isoprenoidal lipids.

385 Taraxerol from R. stylosa was enriched by $\sim 30 \%$ relative to $\beta$-sitosterol and stigmasterol from $A$.

386 marina and by $\sim 60 \%$ relative to stigmastanol from $A$. corniculatum (Figure 2). These

387 differences could be due to the different biosynthetic pathways from which pentacyclic

388 triterpenols and sterols are produced. For example, pentacyclic triterpenols produced by Daucus

389 carota are enriched by 30-60\% relative to sterols produced by the same plant (Sessions et al.,

390 1999), and the pentacyclic triterpenol lupenol is enriched by $30-40 \%$ relative to $\beta$-sitosterol

391 produced by Spartina alterniflora (Sessions, 2006). The observation that the most enriched

392 isoprenoid is from the plant that also produced the most enriched $n$-alkane may therefore be a

393 coincidence.

$394 \quad$ Previous studies observed differences in biosynthetic fractionation up to $70 \%$ among

395 different plants growing at the same site (Feakins \& Sessions, 2010a; Feakins \& Sessions,

396 2010b; Romero \& Feakins, 2011; Eley et al., 2013). It is unlikely that this variability is due to

397 changes in the isotopic fractionation associated with individual biosynthetic steps, which are

398 typically consistent with temperature and reaction rate (Schmidt et al., 2003; Wang et al., 2009). 
399 Rather, variability in $\alpha_{\text {Lipid-Lw }}$ is more likely to be caused by different sources of NADPH,

400 differences in the relative use of stored carbohydrates, or by different timing of lipid production.

401 These possibilities are explored below.

402 The hydrogen in lipids is derived from three sources: intracellular water, carbohydrate

403 molecular precursors, and NADPH (Sessions et al., 1999; Schmidt et al., 2003; Zhang et al.,

404 2009). Of these, variations in the relative amounts of $\mathrm{H}$ from NADPH derived from

405 photosynthesis or from the pentose phosphate cycle have the most potential to profoundly

406 influence $\delta^{2} \mathrm{H}_{\text {Lipid }}$, as $\delta^{2} \mathrm{H}$ values of the two NADPH pools can differ by several hundred per mil

407 (Schmidt et al., 2003; Zhang et al., 2009). The different compatible solutes employed by each

408 species could cause variability in the NADPH sources for lipid synthesis. A. marina produces the

409 amino acids asparagine and glycine betaine as its main compatible solutes (Ashihara et al., 1997;

410 Hibino et al., 2001) while A. corniculatum produces aspartic acid and alanine (Datta \& Ghosh,

411 2003). R. stylosa, on the other hand, primarily uses the soluble carbohydrates pinitol and manitol

412 (Hibino et al., 2001). Because the primary NADPH source of $\mathrm{H}$ to amino acids is the relatively

413 enriched pool from the pentose phosphate cycle (Schmidt et al., 2003), it is possible that the

414 production of amino acid-based compatible solutes in A. marina and A. corniculatum results in

415 relatively more use of depleted NADPH from photosynthesis for lipid synthesis in those two

416 species as compared to R. stylosa.

417 Another possible explanation for variability in biosynthetic fractionation among these

418 mangrove species could be different reliance on stored carbohydrates as lipid precursors. Stored

419 carbohydrates are enriched in ${ }^{2} \mathrm{H}$ relative to current photosynthate, and biosynthetic products

420 derived from stored carbohydrates are likewise enriched in ${ }^{2} \mathrm{H}$ (Yakir \& DeNiro, 1990; Yakir,

421 1992; Roden \& Ehlringer, 2000). If lipid synthesis in R. stylosa is more reliant on stored 
422 carbohydrates than in the other two species, that could account for the observed differences in $n$ -

423 alkane $\delta^{2} \mathrm{H}$ values among species. A. marina is more salt tolerant than $R$. stylosa (Clough, 1984;

424 Naidoo, 1985; Clough \& Sim, 1989), and consistently has higher photosynthetic rates than $R$.

425 stylosa growing at the same site (Clough \& Sim, 1989). A. marina may therefore have more

426 primary photosynthate available for leaf wax synthesis than $R$. stylosa, which may be more likely

427 to rely on stored carbohydrates for lipid production during times of salt stress.

428 Another possibility is that differences in the timing of lipid production account for the

429 differences in $\delta^{2} \mathrm{H}$ values among species. This could include production of lipids at different

430 times of day and during different seasons, as well as different lipid residence times within the

431 leaf. All leaf water measurements made in this study were from leaves collected in the early-to-

432 mid afternoon, in order to capture the maximum diurnal enrichment of leaf water. However, leaf

433 water isotopes fluctuate throughout the day with changes in relative humidity, temperature and

434 stomatal conductance (Kahmen et al., 2008; Ferrio et al., 2009). If $R$. stylosa fixes a larger

435 proportion of carbon during the afternoon, when leaf water is most enriched, it would be

436 expected to have more enriched lipids than A. marina or A. corniculatum if they fix a larger

437 fraction of carbon in the morning and/or evening.

438 Daily water use patterns and photosynthetic activity differ for adjacent $R$. stylosa and $A$.

439 marina growing on North Stradbroke Island, $\sim 200 \mathrm{~km}$ north of Mobbs Bay (Vandegehuchte et

440 al., 2014). Stomatal resistance in $R$. stylosa is relatively constant throughout daylight hours,

441 while $A$. marina has much higher stomatal resistance rates during the afternoon than in the

442 morning or evening (Vandegehuchte et al., 2014). This pattern is consistent with $A$. marina being

443 more photosynthetically active during cooler parts of the day, when leaf water should be less

444 enriched, which would result in relatively depleted leaf waxes. 
Another possibility is that different species may produce lipids during different seasons.

446 Temperate plants typically produce leaf waxes soon after leaf flush in the spring, and some

447 studies have shown the isotopic signature of leaf waxes during this time of high production

448 persists throughout the growing season (Sachse et al., 2010; Tipple et al., 2013), while other

449 work indicates that leaf waxes are regenerated and isotopically variable over time (Sachse et al.,

450 2009; Gao et al., 2012; Gao \& Huang, 2013). Leaf production in mangroves, and other tropical

451 evergreen plants, is not limited to one season and occurs throughout the year (Wium-Andersen \&

452 Christensen, 1978; Duke et al., 1984; Coupland et al., 2005). Seasonal variability in afternoon

$453 \delta^{2} \mathrm{H}_{\mathrm{LW}}$ values in Mobbs Bay was more than $60 \%$ in both A. marina and R. stylosa (Figures 2

454 and 3). If $R$. stylosa produces relatively more leaf lipids during drier seasons, when $\delta^{2} \mathrm{H}_{\mathrm{LW}}$

455 values are high, it would have ${ }^{2} \mathrm{H}$-enriched lipids compared to A. marina and A. corniculatum.

456 In studies of leaf longevity from Phuket, Thailand, and Darwin, Australia, Rhizophora

457 leaves had greater average longevity than A. marina leaves (Wium-Andersen \& Christensen,

458 1978; Coupland et al., 2005). Rhizophora leaves persisted on average for $11.2 \pm 0.2$ months, as

459 compared to A. marina leaves, which lasted an average of $6.3 \pm 0.1$ months. If $R$. stylosa has the

460 longest leaf residence time among Mobbs Bay mangroves, its $\delta^{2} \mathrm{H}_{\text {Lipid }}$ values might be more

461 reflective of average conditions in Mobbs Bay throughout the year, while lipids in A. marina

462 leaves would be more responsive to changing environmental conditions.

463 Likewise, lipid turnover in existing leaves could account for differences among species.

464 While most leaf waxes are produced soon after leaf flush, new waxes can form on mature leaves

465 that have been abraded by wind, rain, or fauna, changing the overall $\delta^{2} \mathrm{H}_{\mathrm{Wax}}$ values (Sachse et al.,

466 2009; Gao et al., 2012; Gao \& Huang, 2013). If A. marina and A. corniculatum leaf waxes are

467 more susceptible to abrasion during rain events, and are subsequently regenerated using the 
468 relatively fresher, isotopically depleted water associated with those storms, their lipids would be

469 less enriched than those of R. stylosa. Lipid turnover rates have not been investigated for sterols

470 and triterpenols, which are not part of the epicuticular wax, but are located in sub-epidermal

471 parts of the leaf. These compounds are likely less susceptible to abrasion than waxes, and the fact

472 that changes in their $\delta^{2} \mathrm{H}$ values do not covary with those of $n$-alkanes (Figure 2) suggests that

473 different factors control the residence times of different lipid classes.

\section{Relationship between salinity and net isotopic fractionation in mangrove lipids}

476 Net fractionation during mangrove lipid synthesis, $\alpha_{\text {Lipid-Sw, was inversely related to }}$

477 salinity (Figure 6), as observed previously for A. marina growing along the Brisbane River

478 (Ladd \& Sachs, 2012) and for Rhizophora spp. growing along estuaries in Micronesia and

479 around marine lakes in Palau (Ladd \& Sachs, in review). Part of this dependence was driven by

480 changes in $\delta^{2} \mathrm{H}_{\mathrm{Sw}}$ values, which were large and positively correlated with salinity (Figure 3),

481 making it more appropriate to look at lipid $\delta^{2} \mathrm{H}$ values in order to assess changes in lipid

482 composition due to variable salinity (Figure $2 \mathbf{d}$ and 2e). Changes in $\delta^{2} \mathrm{H}_{\mathrm{Sw}}$ alone do not explain

483 the decreases in $\alpha_{\text {Lipid-Sw }}$ at higher salinities, as $\delta^{2} \mathrm{H}_{\text {Lipid }}$ values decreased for 7 of the 10 lipids

484 studied here even as $\delta^{2} \mathrm{H}_{\mathrm{Sw}}$ values increased (Figure 2d and 2e). These results contribute to the

485 growing body of evidence that mangroves discriminate more strongly against ${ }^{2} \mathrm{H}$ during lipid

486 synthesis as salinity increases, regardless of species or local climate (Ladd \& Sachs, 2012; Ladd

$487 \&$ Sachs, in review).

488 The results of this study make it possible to reevaluate the hypotheses initially proposed

489 to explain the inverse relationship between salinity and net isotopic fractionation in mangroves

490 by Ladd and Sachs (2012). One hypothesis was that discrimination against ${ }^{2} \mathrm{H}$ during water 
491 uptake increased with increasing salinity. The data presented here do not support this hypothesis.

492 While all three species discriminated against ${ }^{2} \mathrm{H}$ during water uptake, there was no systematic

493 change in the magnitude of that fractionation as a function of salinity (Figure 7). The decrease in

$494 \alpha^{2}$ XW-Sw as salinity increased was associated with a decrease in $\alpha^{18}$ XW-Sw (Figure 4), which has

495 not been observed to be sensitive to water isotope fractionation by roots (Lin \& Sternberg, 1993;

496 Ellsworth \& Williams, 2007), and is thus more plausibly explained by the opportunistic

497 utilization of fresher, more depleted water.

498 The utilization of isotopically depleted, fresher water sources at higher salinity cannot

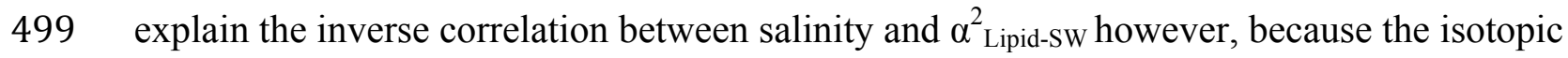

500 depletion in the xylem water is not observed in the leaf water from which leaf lipids are

501 synthesized (Figures 5). Since there is no change in $\alpha^{2}$ LW-SW with salinity (Figures 5a-5c), the

502 decrease in $\delta^{2} \mathrm{H}_{\mathrm{XW}}$ values relative to $\delta^{2} \mathrm{H}_{\mathrm{SW}}$ values, while interesting from the perspective of

503 salinity tolerance and water use by mangroves, is less relevant to understanding the mechanism

504 responsible for the inverse relationship between salinity and $\alpha_{\text {Lipid-Sw. }}$

505 Likewise, the fact that there are no systematic decreases in net leaf water enrichment with

506 increasing salinity argues against the third hypothesis proposed by Ladd and Sachs (2012), which

507 is based on increased salt secretion by A. marina at higher salinity. We hypothesized that

508 hydration of salts on the surfaces of leaves could diminish leaf-water ${ }^{2} \mathrm{H}$-enrichment by both

509 lowering the vapor-pressure differential across the leaf surface, and by depleting the $\delta^{2} \mathrm{H}$ value of

510 water vapor near the leaf surface (since hydration water of salts is ${ }^{2} \mathrm{H}$-depleted relative to water

511 vapor (Matsuo et al.,1972)). Both of these hypotheses were based on increased salt on the leaf

512 surface at high salinity. As such, they should be more pronounced for the salt secreting

513 mangroves $A$. marina and $A$. corniculatum. Since there was no difference in $\alpha^{2}$ LW-Sw between the 
514 salt secreting mangroves with salt-coated leaves and the non-secreting tree with no visible salt

515 deposits on its leaves, and since there was no relationship between salinity and $\alpha_{\text {LW-Sw }}^{2}$ in any of

516 the three species (Figure 5), it seems unlikely that the hypothesis relating salt on the leaf surface

517 to reduced leaf water enrichment is correct.

518 Ultimately, the entire variability in apparent fractionation between leaf lipids and source

519 water in Mobbs Bay mangroves must be explained either by variability in biosynthetic

520 fractionation, $\alpha_{\text {Lipid-LW, }}$ or by variable lipid production in response to fluctuating salinity. Salinity

521 dependent changes in $\alpha_{\text {Lipid-LW }}$ can account for differences among species and for differences

522 within an individual tree. The second hypothesis posed by Ladd and Sachs (2012) to explain the

523 Brisbane River data, that increased compatible solute production at high salinity results in less $\mathrm{H}$

524 from NADPH derived via the pentose phosphate cycle being incorporated into lipids, is the only

525 previously proposed hypothesis that would manifest itself as changes in $\alpha_{\text {Lipid-LW. However, the }}$

526 data presented here cannot confirm or refute this hypothesis. Other processes described above

527 that could result in differences in $\alpha_{\text {Lipid-LW }}$ among species, such as variability in the amount of

528 stored carbohydrates used for lipid synthesis, could also explain differences in $\alpha_{\text {Lipid-LW }}$ within a

529 species over time, as in this study, or over spatial salinity gradients (Ladd \& Sachs, 2012; Ladd

$530 \&$ Sachs, in review). While the data here does not definitively explain why there would be more

531 biosynthetic discrimination against ${ }^{2} \mathrm{H}$ at higher salinity, it does suggest that this is a promising

532 avenue for further investigation of the mechanisms responsible for the inverse relationship

533 between salinity and $\alpha_{\text {Lipid-Sw. }}$

534 Alternatively, some or all of the observed salinity dependence of $\alpha_{\text {Lipid-sw }}$ for mangrove

535 lipids (Figure 6), could be due to variable rates of leaf and leaf lipid production in response to

536 salinity. If mangroves in seasonal locations such as Mobbs Bay preferentially produce leaves and 
537 leaf lipids during rainy periods when salinity and $\delta^{2} \mathrm{H}_{\mathrm{Sw}}$ are low, the apparent net fractionation

538 and apparent biosynthetic fractionation would appear larger during times of high salinity, when

$539 \delta^{2} \mathrm{H}_{\mathrm{SW}}$ and $\delta^{2} \mathrm{H}_{\mathrm{LW}}$ are relatively high (Figure 2). Since mangrove leaves are produced throughout

540 the year (Wium-Andersen \& Christensen, 1978; Duke et al., 1984; Coupland et al., 2005), and

541 since leaf lipids can be regenerated over the existence of a leaf (Sachse et al., 2009; Gao et al.,

542 2012), the influence of newly synthesized lipids would be muted by the continued presence of

543 older compounds.

544

\section{CONCLUSIONS}

$546 \quad \delta^{2} \mathrm{H}$ values of leaf lipids and $\delta^{2} \mathrm{H}$ and $\delta^{18} \mathrm{O}$ values of surface, xylem, and leaf water were

547 measured weekly in R. stylosa, A. marina, and A. corniculatum mangroves in Mobbs Bay, New

548 South Wales, Australia over 9.5 months. When salinity exceeded $20 \mathrm{ppt}$, xylem water $\delta^{18} \mathrm{O}$

549 values decreased relative to surface water, suggesting that the mangroves relied more on non-

550 surface water sources, such as groundwater, episodic rain events and/or foliar water uptake. Even

551 at times when there was no ${ }^{18} \mathrm{O}$-depletion, xylem water $\delta^{2} \mathrm{H}$ was depleted by $4-10 \%$ relative to

552 estuary surface water in all three species, implying discrimination against ${ }^{2} \mathrm{H}$ during water

553 uptake.

$554 \quad$ Although xylem water became more ${ }^{2} \mathrm{H}$ - and ${ }^{18} \mathrm{O}$-depleted relative to surface water as

555 salinity increased from 1-36 ppt, there were no systematic changes in leaf water $\delta^{2} \mathrm{H}$ or $\delta^{18} \mathrm{O}$

556 values relative to surface water. Leaf water $\delta^{2} \mathrm{H}$ values were also similar among species. In all

557 three species, the ${ }^{2} \mathrm{H}$-depletion in leaf lipids relative to estuary and leaf water increased with

558 salinity by $0.5-1.0 \% \mathrm{ppt}^{-1}$ in $n$-alkanes and by $0.4-0.8 \% \mathrm{ppt}^{-1}$ in isoprenoids. Since there were no

559 systematic changes in leaf water enrichment with salinity, changes in leaf and xylem water $\delta^{2} \mathrm{H}$ 
560 values cannot explain the salinity dependence of ${ }^{2} \mathrm{H}$-depletion in leaf lipids. More likely causes

561 are (i) increased compatible solute production at high salinity causing changes in the source of

562 NADPH used in lipid synthesis, (ii) reduced utilization of stored carbohydrates for lipid

563 synthesis as salinity increases, or (iii) variability in the timing of lipid production and turnover

564 rates. An $\sim 30 \%{ }^{2} \mathrm{H}$ enrichment of $n$-alkanes and isoprenoids in $R$. stylosa leaves relative to the

565 other two species can be explained by either different classes of compatible solutes, a different

566 proportional reliance on stored carbohydrates in lipid synthesis, different timing of leaf lipid

567 production, or different turnover rates of leaves and/or leaf lipids compared to A. marina and $A$.

568 corniculatum.

569 Further investigation into the causes of biosynthetic fractionation in leaf lipids and into

570 the timing of lipid production and replacement rates in mangroves will better constrain the use of

$571 \delta^{2} \mathrm{H}_{\text {lipid }}$ values from mangroves as a paleohydrologic proxy, and offer improved understanding of

572 carbon and lipid metabolisms within trees.

573

574 ACKNOWLEDGEMENTS

575 This research was funded by NSF grant No. EAR-1348396 (J.P.S.), a University of

576 Washington Royalty Research Fund grant (J.P.S.), and an NSF Graduate Research Fellowship

577 (N.L.). Bradley Eyre and Southern Cross University hosted J.P.S. during a sabbatical so the

578 sampling of mangroves for this study could be accomplished. Amy Duncan assisted with the

579 fieldwork. Ariel Townsend and Josh Gregersen assisted with sample preparation and instrument

580 maintenance. We had productive conversations with Dan Nelson, Ashley Maloney, Ansgar

581 Kahmen, Paul Quay, Anitra Ingalls, Ruth Reef, and Liz van Volkenberg that improved our

582 experimental design and data analysis. Ansgar Kahmen was generous in the use of his lab for 
583 leaf and xylem water extractions and TCEA measurements. Dan Nelson and Oliver Rach

584 measured leaf and xylem water isotopes at the University of Basel. Two anonymous reviewers

585 provided insightful comments that helped improve this manuscript. We are grateful for all of

586 their contributions.

588 References

589

590

591

592

593

594

595

596

597

598

599

600

601

602

603

604

605

606

607

608

609

610

611

612

613

614

615

616

617

618

619

620

Alongi D.M. \& Mukhopadhyay S.K. (2014) Contribution of mangroves to coastal carbon cycling in low latitude seas. Agricultural and Forest Meterology doi:10.1016/j.agrformet.2014.10.005

Ashihara H., Adachi K., Otawa M., Yasumoto E., Fukushima Y., Kato M., Sano H., Sasamoto H. $\&$ Baba S. (1997) Compatible solutes and inorganic ions in the mangrove plant Avicennia marina and their effects on the activities of enzymes. Zeitschrift für Naturforschung 52, 433-440.

Burgess S.S.O. \& Dawson T.E. (2004) The contribution of fog to the water relations of Sequoia sempervirens (D. Don): foliar uptake and prevention of dehydration. Plant, Cell and Environment 27, 1023-1034.

Clough B.F. (1984) Growth and salt balance of the mangroves. Avicennia marina (Forsk.) Vierh. and Rhizophora stylosa Griff. in relation to salinity. Australian Journal of Plant Physiology 11, 419-430

Clough B.F. \& Sim, R.G. (1989) Changes in gas exchange characteristics and water use efficiency of mangroves in response to salinity and vapour pressure deficit. Oecologia 79, 38-44.

Coupland G.T., Paling E.I. \& McGuinness K.A. (2005) Vegetative and reproductive phenologies of four mangrove species from northern Australia. Australian Journal of Botany 53, 109117.

Craig H. \& Gordon L. (1965) Deuterium and oxygen 18 variations in the ocean and the marine atmosphere. In: Tongiori, E. (Ed.), Proceedings of a Conference on Stable Isotopes in Oceanographic Studies and Paleotemperatures. CNR-Laboratorio di Geologia Nucleare, Pisa, pp. 9-130.

Dansgaard W. (1964) Stable isotopes in precipitation. Tellus 16, 436-468.

Datta P.N. \& Ghose M. (2003) Estimation of osmotic potential and free amino acids in some mangroves of the Sundarbans, India. Acta Botanica Croatica 62, 37-45.

De Groote S. (2013) Impact of dew and rain on the water relations of the mangrove species Avicennia marina (Forssk.) Vierh.Master's thesis, University Ghent, Faculty of Bioscience Engineering.

Douglas P.J.M., Pagani M., Brenner M., Hodell D.A. \& Curtis J.H. (2012) Aridity and vegetation composition are important determinants of leaf-wax $\delta \mathrm{D}$ values in southeastern Mexico and Central America. Geochimica et Cosmochimica Acta 97, 24-45. 
Duke N.C., Bunt J.S. \& Williams W.T. (1984) Observations of the floral and vegetative phenologies of north-eastern Australian mangroves. Australian Journal of Botany 32, 8799.

Eley Y., Dawson L., Black S., Andrews J. \& Pedentchouk N. (2013) Understanding 2H/1H systematics of leaf wax n-alkanes in coastal plants at Stiffkey saltmarsh, Norfolk, UK. Geochimica et Cosmochimica Acta 128, 13-28.

Eller C.B., Lima A.L. \& Oliveira R.S. (2013) Foliar uptake of fogwater and transport belowground alleviates drought effects in the cloud forest tree species, Drimys brasiliensis (Winteraceae). New Phytologist 199, 151-162.

Ellsworth P. \& Williams D. (2007) Hydrogen isotope fractionation during water uptake by woody xerophytes. Plant and Soil 291, 93-107.

Ewe S., Sternberg L. \& Childers D. (2007) Seasonal plant water uptake patterns in the saline southeast Everglades ecotone. Oecologia 152, 607-616.

Feakins S.J. \& Sessions A.L. (2010a) Crassulacean acid metabolism influences D/H ratio of leaf wax in succulent plants. Organic Geochemistry 41, 1269-1276.

Feakins S.J. \& Sessions A.L. (2010b) Controls on the D/H ratios of plant leaf waxes in an arid ecosystem. Geochimica Cosmochimica Acta 74, 2128-2141.

Ferrio J.P., Cuntz M., Offermann C., Siegwolf R., Saurer M. \& Gessler A. (2009) Effect of water availablility on leaf water isotopic enrichment in beech seedlings shows limitations of current fractionation models. Plant, Cell and Environment, 32, 1285-1296.

Gao L., Burnier A. \& Huang Y. (2012) Quantifying instantaneous regeneration rates of plant leaf waxes using stable hydrogen isotope labeling. Rapid Communications in Mass Spectrometry, 26, 115-122.

Gao L. Edwards E.J., Zeng Y. \& Huang Y. (2014) Major evolutionary trends in hydrogen isotope fractionation of vascular plant leaf waxes. PLOS one, DOI: 10.1371/journal.pone.0112610

Gao L. \& Huang Y. (2013) Inverse gradients in leaf wax $\delta D$ and $\delta 13 C$ values along the grass blades of Micanthus sinensis: implications for leaf wax reproduction and plant physiology. Oecologia, DOI: 10.1007/s00442-012-2506-6

Gat J.R. (1996) Oxygen and hydrogen isotopes in the hydrologic cycle. Annual Review in Earth and Planetary Sciences 24, 225-262.

Hao G.Y., Jones, T.J., Luton, C., Zhang, Y.J., Manzane, E., Scholz, F.G., Bucci, S.J., Cao, K.F. \& Goldstein, G. (2009) Hydraulic redistribution in dwarf Rhizophora mangle trees driven by interstitial soil water salinity gradients: impacts on hydraulic architecture and gas exchange. Tree Physiology 29, 697-705.

Hibino T., Meng Y.L., Kawamitsu Y., Uehara N., Matsuda N., Tanaka Y., .., Takabe T., 2001. Molecular cloning and functional characterization of two kinds of betaine-aldehyde dehydrogenase in betaine-accumulating mangrove Avicennia marina (Forsk.) Vierh. Plant Molecular Biology 45, 353-363.

Hou J., D'Andrea W. \& Huang Y. (2008) Can sedimentary leaf waxes record D/H ratios of continental precipitation? Field, model and experimental assessments. Geochimica et Cosmochimica Acta 72, 3503-3517.

Hou J., D'Andrea W., MacDonald D. \& Huang Y.S. (2007) Hydrogen isotopic variability in leaf waxes among terrestrial and aquatic plants around Blood Pond, Massachusetts (USA). Organic Geochemistry 38, 977-984. 
Huang Y., Shuman B., Wang Y. \& Webb T. (2004) Hydrogen isotope ratios of individual lipids in lake sediments as novel tracers of climatic and environmental change: a surface sediment test. Journal of Paleolimnology 31, 363-375.

Johnson D.M. \& Smith W.K. (2008) Cloud immersion alters microclimate, photo- synthesis and water relations in Rhododendron catawbiense and Abies fraseri seedlings in the southern Appalachian Mountains, USA. Tree Physiology 28, 385-392.

Kahmen A., Hoffmann B., Schefuss E., Arndt S.K., Cernusak L.A., West J.B. \& Sachse D. (2013a) Leaf water deuterium enrichment shapes leaf wax n-alkane $\mathrm{dD}$ values of angiosperm plants II: Observational evidence and global implications. Geochimica et Cosmochimica Acta 111, 50-63.

Kahmen A., Schefuss E. \& Sachse D. (2013b) Leaf water deuterium enrichment shapes leaf wax n-alkane $\mathrm{dD}$ values of angiosperm plants I: Experimental evidence and mechanistic insights. Geochimica et Cosmochimica Acta 111, 39-49.

Kahmen A., Simonin K., Tu K.P., Merchant A. \& Callister A. (2008) Effects of environmental parameters, leaf physiological properties and leaf water relations on leaf water delta ${ }^{18} \mathrm{O}$ enrichment in different Eucalyptus species. Plant, Cell \& Environment 31, 738-751.

Ladd S.N. \& Sachs J.P. (2012) Inverse relationship between salinity and $n$-alkane $\delta$ D values in the mangrove Avicennia marina. Organic Geochemistry 48, 25-36.

Ladd S.N. \& Sachs J.P. (in review) Influence of salinity on hydrogen isotope fractionation in Rhizophora mangroves from Micronesia. Geochimica et Cosmichimica Acta.

Lambs L., Muller E. \& Fromard F. (2008) Mangrove trees growing in a very saline condition but not using seawater. Rapid Communications in Mass Spectrometry 22, 2835-2843.

Lin G. \& Sternberg L. (1993) Hydrogen isotopic fractionation by plant roots during water uptake in coastal wetland plants. In Stable Isotopes and Plant Carbon/Water Relations (eds Ehleringer, J., Hall, A. \& Farquhar, G.), pp. 497-510. Academic Press, Inc., San Diego.

Lin G. \& Sternberg L. (1994) Utilization of surface water by red mangrove (Rhizophora mangle L.): An isotopic study. Bulletin of Marine Science 54, 94-102.

Liu W.G. \& Yang H. (2008) Multiple controls for the variability of hydrogen isotopic compositions in higher plant $n$-alkanes from modern ecosystems. Global Change Biology 14, 2166-2177.

Liu W.G., Yang H. \& Li L. (2006) Hydrogen isotopic composition of $n$-alkanes from terrestrial plants correlate with their ecological life form. Oecologia 150, 330-338.

Matsuo S., Friedman I. \& Smith G.I. (1972) Studies of quaternary saline lakes - I. Hydrogen isotope fractionation in saline minerals. Geochimica et Cosmochimica Acta 36, 427-435.

Naidoo G. (1985) Effects of waterlogging and salinity on plant-water relations and on the accumulation of solutes in three mangrove species. Aquatic Botany 22, 133-143.

Polissar P.J. \& Freeman K.H. (2010) Effects of aridity and vegetation on plant-wax $\delta \mathrm{D}$ in modern lake sediments. Geochimica et Cosmochimica Acta 74, 5785-5797.

Rada F., Goldstein G., Orozco A., Montilla M., Zabala O. \& Azócar A. (1989) Osmotic and turgor relations of three mangrove ecosystem species. Functional Plant Biology 16, 477486.

Reef R. \& Lovelock C.E. (2015) Regulation of water balance in mangroves. Annals of Botany $155,385-395$.

Reef R., Markham H.L., Santini N.S. \& Lovelock C.E. (2015) The response of the mangrove Avicennia marina to heterogeneous salinity measured using a split-root approach. Plant and Soil, doi 10.1007/s11104-015-2489-2. 
Roden J.S., Lin G. \& Ehleringer J.R. (2000) A mechanistic model for interpretation of hydrogen and oxygen isotope ratios in tree-ring cellulose. Geochimica et Cosmochimica Acta 64, 21-35.

Romero I.C. \& Feakins S.J. (2011) Spatial gradients in plant leaf wax D/H across a coastal salt marsh in southern California. Organic Geochemistry 42, 618-629.

Sachse D., Billault I., Bowen G.J., Chikaraishi Y., Dawson T.E., Feakins S.J., ... Kahmen A. (2012) Molecular paleohydrology: interpreting the hydrogen-isotopic composition of lipid biomarkers from photosynthesizing organisms. Annual Review of Earth and Planetary Science 40, 212-249.

Sachse D., Dawson T. \& Kahmen A. (2015) Seasonal variation of leaf wax $n$-alkane production and $\delta^{2} \mathrm{H}$ values from the evergreen oak tree, Quercus agrifolia. Isotopes in Environmental Health and Sciences 51, 1-19.

Sachse D., Gleixner G., Wilkes H. \& Kahmen A. (2010) Leaf wax $n$-alkane $\delta$ D values of fieldgrown barley reflect leaf water $\delta \mathrm{D}$ values at the time of leaf formation. Geochimica et Cosmochimica Acta 74, 6741-6750.

Sachse D., Kahmen A. \& Gleixner G. (2009) Significant seasonal variation in the hydrogen isotopic composition of leaf-wax lipids for two deciduous tree ecosystems (Fagus sylvativa and Acer pseudoplatanus). Organic Geochemistry 40, 732-742.

Sachse D., Radke J. \& Gleixner G. (2004) Hydrogen isotope ratios of recent lacustrine sedimentary $n$-alkanes record modern climate variability. Geochimica et Cosmochimica Acta 68, 4877-4889.

Santini N.S., Reef R., Lockington D.A. \& Lovelock C.E. (2015) The use of fresh and saline water sources by the mangrove Avicennia marina. Hydrobiologia 745, 59-68.

Schmidt H.L., Werner R.A. \& Eisenreich W. (2003) Systematics of ${ }^{2}$ H patterns in natural compounds and its importance for the elucidation of biosynthetic pathways. Phytochemistry Reviews 2, 61-85.

Sessions A. (2006) Seasonal changes in $\mathrm{D} / \mathrm{H}$ fractionation accompanying lipid biosynthesis in Spartina alterniflora. Geochima et Cosmochimica Acta 70, 2153-2162.

Sessions A.L., Burgoyne T.W., Schimmelmann A. \& Hayes J. M. (1999) Fractionation of hydrogen isotopes in lipid biosynthesis. Organic Geochemistry 30, 1193-1200.

Smith F.A. \& Freeman K.H. (2006) Influence of physiology and climate on $\delta$ D of leaf wax $n$ alkanes from $\mathrm{C}_{3}$ and $\mathrm{C}_{4}$ grasses. Geochimica et Cosmochimica Acta 70, 1172-1187.

Tipple B.J., Berke M.A., Doman C.E., Khachaturyan S. \& Ehleringer J.R. (2013) Leaf n- alkane record the plant-water environment at leaf flush. Proceedings of the National Academy of Science 110, 2659-2664.

Tipple B.J., Berke M., Hambach B., Roden J.S. \& Ehleringer J.R. (In Press) Predicting leaf wax n-alkane (2) H/(1) H ratios: controlled water source and humidity experiments with hydroponically grown trees confirm predictions of Craig-Gordon model. Plant, Cell and Environment. doi: $10.1111 /$ pce.12457.

Tipple B.J. \& Pagani M. (2013) Environmental control on eastern broadleaf forest species' leaf wax distributions and D/H ratios. Geochimica et Cosmochimica Acta 111, 64-77.

Vandegehuchte M.W., Guyot A., Hubau M., DeGroote S.R.E., De Baerdemaeker N.J.F., Hayes M., ..., Steppe K. (2014) Long-term versus daily stem diameter variation in co-occurring mangrove species: environmental versus ecophysiological drivers. Agricultural and Forest Meteorology 192-193, 51-58. 
Wang Y, Sessions A.L., Nielsen R.J. \& Goddard W.A. (2009) Equilibrium ${ }^{2} \mathrm{H} /{ }^{1} \mathrm{H}$ fractionations in organic molecules. II. Linear alkanes, alkenes, ketones, carboxylic acids, esters, alcohols and ethers. Geochimica et Cosmochimica Acta 73, 7076-7086.

West A.G., Patrickson S.J. \& Ehleringer J.R. (2006) Water extraction times for plant and soil materials used in stable isotope analysis. Rapid Communications in Mass Spectrometry 20, 1317-1321.

Wei L., Lockington D.A., Poh S.C., Gasparon M. \& Lovelock C.E. (2013) Water use patterns of estuarine vegetation in a tidal creek system. Oecologia 172: 485-494.

Wium-Andersen S. \& Christensen B. (1978) Seasonal growth of mangrove trees in southern Thailand. II. Phenology of Brugueira cylindrica, Ceriops tagal, Lumnitzera littoria and Avicennia marina. Aquatic Botany 5, 383-390.

Yakir D. (1992) Variations in the natural abundance of ${ }^{18} \mathrm{O}$ and deuterium in plant carbohydrates. Plant, Cell and Environment 15, 1005-1020.

Yakir D. \& DeNiro M.J. (1990) Oxygen and hydrogen isotope fractionation during cellulose metabolism in Lemna gibba L. Plant Physiology 93, 325-332.

Yang H., Pagani M., Briggs D.E.G., Equiza M.A., Jagels R., Leng Q. \& LePage B.A. (2009) Carbon and hydrogen isotope fractionation under continuous light: implications for paleoenvironmental interpretations of the High Arctic during Paleogene warming. 160, 461-470.

Zhang X., Gillespie A. \& Sessions A. (2009) Large D/H variations in bacterial lipids reflect central metabolic pathways. Proceedings of the National Academy of Sciences 106, 12580-12586. 


\section{Figure Captions}

Figure 1 Study site in Ballina, New South Wales. Satellite image from Google Earth.

Figure 2: Rainfall amount (black bars, panel a), salinity (blue circles, panel a), $\delta^{18} \mathrm{O}$ (panel b) and $\delta^{2} \mathrm{H}$ (panel c) of surface (SW), xylem (XW), and leaf (LW) water, and $\delta^{2} \mathrm{H}$ of $n$ alkanes (panel d) and isoprenoidal lipids (panel e) from October 1, 2012 to July 17, 2013. In all panels, Rs is $R$. stylosa (red symbols), Am is A. marina (gray symbols), and Ac is A. corniculatum (purple symbols). Error bars represent one standard deviation of triplicate measurements.

Figure 3 Surface (SW, blue), xylem (XW) and leaf (LW) water $\delta^{18} \mathrm{O}$ values (panels a-c) and $\delta^{2} \mathrm{H}$ values (panels d-f) for $R$. stylosa (red, panels a and d), A. marina (gray, panels $\mathrm{b}$ and e) and A. corniculatum (purple, panels $\mathrm{c}$ and $\mathrm{f}$ ) growing in Mobbs Bay as a function of salinity. X-error bars indicate the precision of the refractometer used to measure salinity. $\mathrm{Y}$-error bars represent the standard deviation of triplicate measurements. Regression lines and $95 \%$ confidence intervals are shown for relationships at are significantly correlated at the $\mathrm{p}<0.05$ level.

Figure 4 Fractionation factors between xylem water and surface water for hydrogen isotopes (panels a-c) and oxygen isotopes (panels d-f) for $R$. stylosa (white squares, panels a \& d), A. marina (gray diamonds, panels $\mathrm{b} \& \mathrm{e}$ ) and A. corniculatum (black circles, panels $\mathrm{c} \&$ f) growing in Mobbs Bay as a function of salinity. X-error bars indicate the precision of the refractometer used to measure salinity. Y-error bars represent the standard deviation of triplicate measurements. Regression lines and $95 \%$ confidence intervals are shown for relationships at are significantly correlated at the $\mathrm{p}<0.05$ level.

Figure 5 Figure 5 Fractionation factors between leaf water and surface water for hydrogen

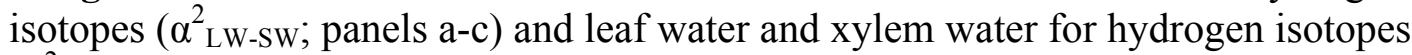
$\left(\alpha_{\text {LW-Xw; }}^{2}\right.$ panels d-f) for $R$. stylosa (white squares, panels a \& d), A. marina (gray diamonds, panels $\mathrm{b} \& \mathrm{e}$ ) and $A$. corniculatum (black circles, panels $\mathrm{c} \& \mathrm{f}$ ) growing in Mobbs Bay as a function of salinity. X-error bars indicate the precision of the refractometer used to measure salinity. Y-error bars represent the standard deviation of triplicate measurements.

Figure 6 Net fractionation factors between leaf lipids and surface water for $n$-alkanes (panel a) and isoprenoids (panel b) for $R$. stylosa (Rs, red), A. marina (Am, gray) and $A$. corniculatum (Ac, purple) growing in Mobbs Bay as a function of salinity. X-error bars indicate the precision of the refractometer used to measure salinity. Y-error bars represent the standard deviation of triplicate measurements. Regression lines and $95 \%$ confidence intervals are shown for relationships at are significantly correlated at the $\mathrm{p}<0.05$ level.

Figure 7 Predicted and measured xylem water $\delta^{2} \mathrm{H}$ values for (a) R. stylosa (Rs), (b) A. marina (Am) and (c) A. corniculatum (Ac) growing in Mobbs Bay from October 1, 2012 to July 17,2013 . Predicted xylem water $\delta^{2} \mathrm{H}$ values are based on measured $\delta^{18} \mathrm{O}$ values of xylem 
water and the local water line. Error bars on measured lines represent one standard 


\section{Figure 1}

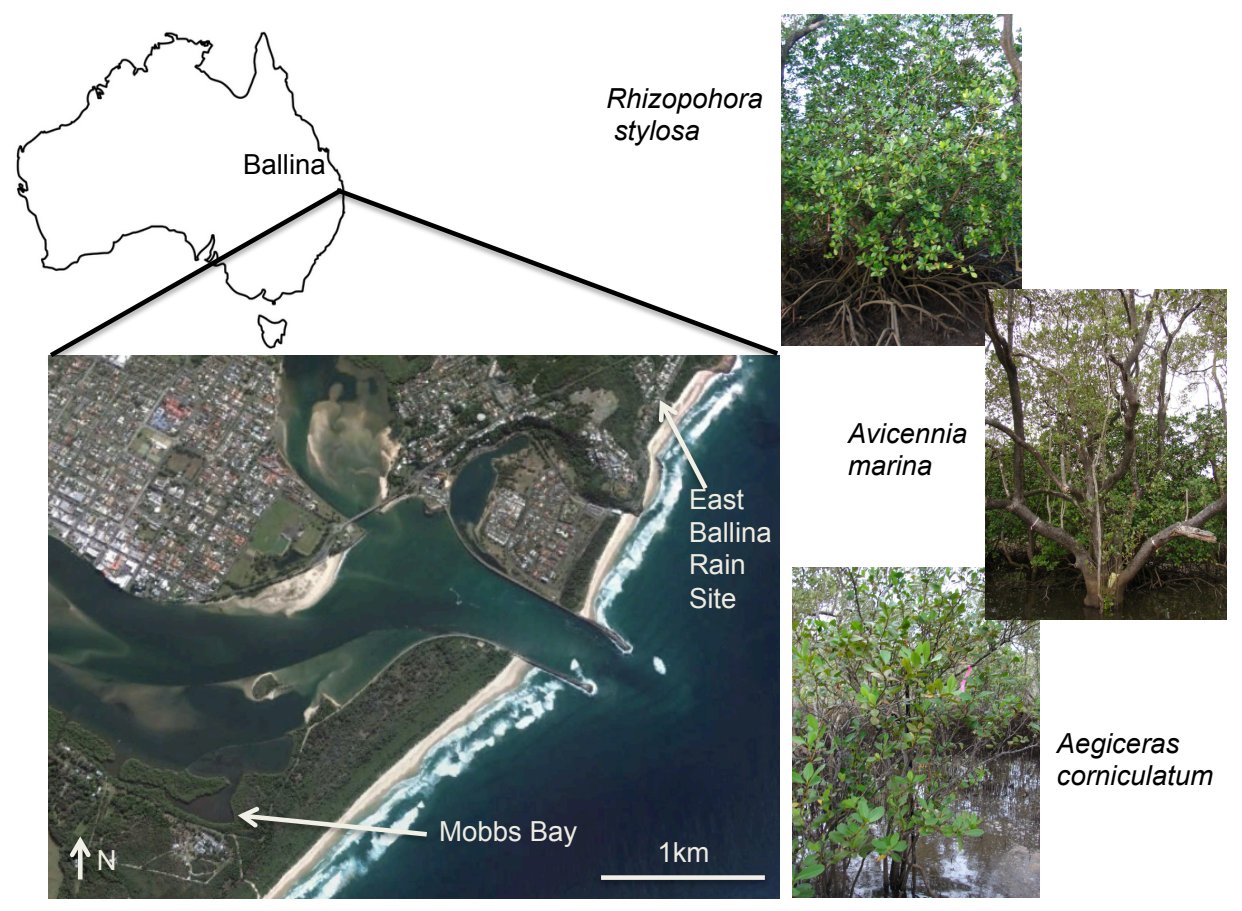

Figure 1 Study site in Ballina, New South Wales and sampled trees 
Day of experiment

e)

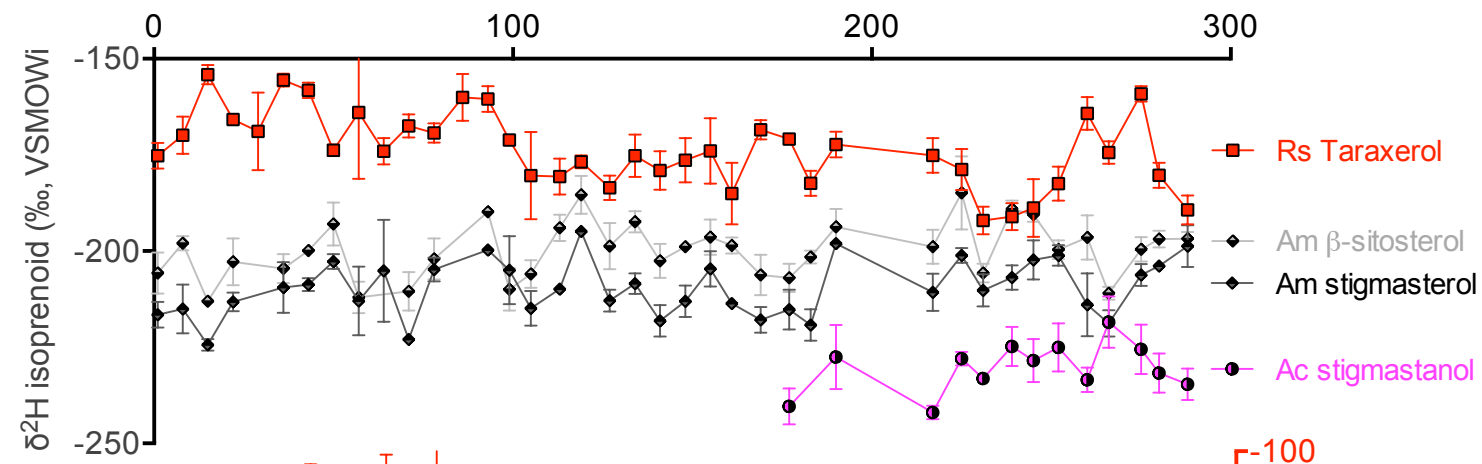

d)

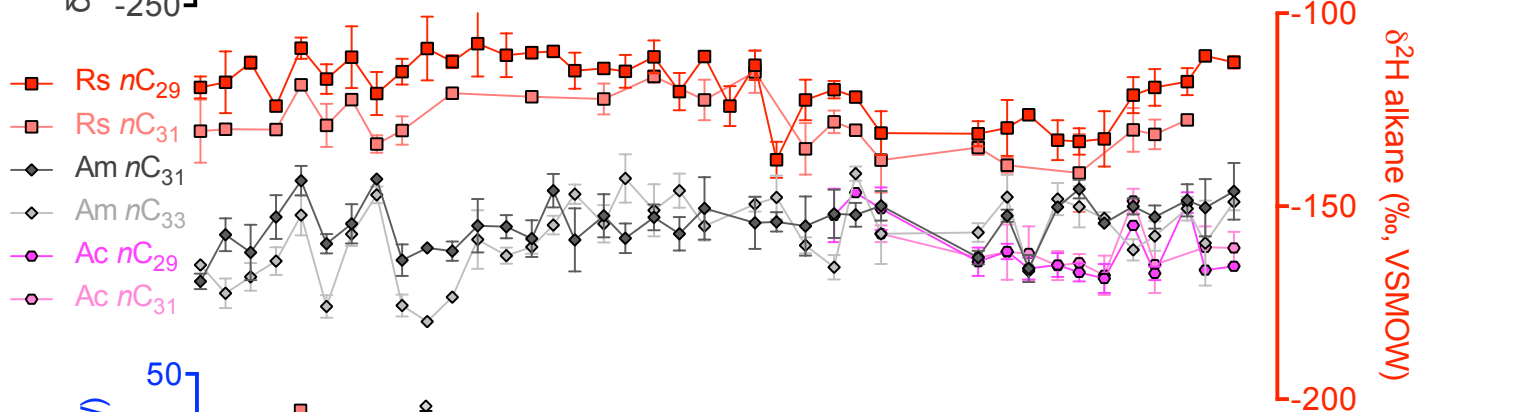

c)

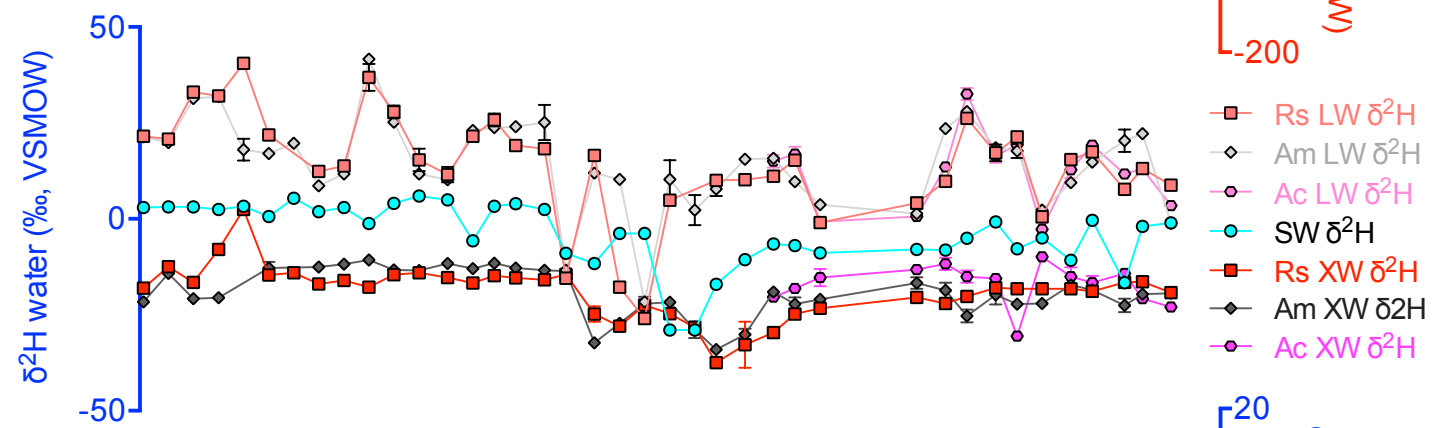

b)

a)

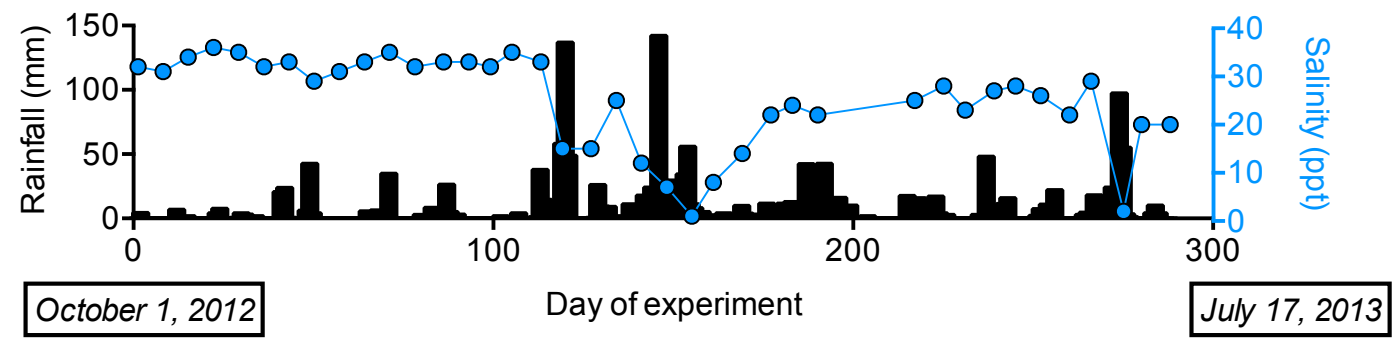

858

859 


\section{$860 \quad$ Figure 3}

a)

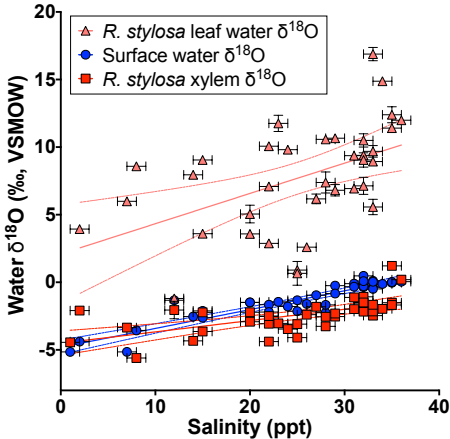

b)

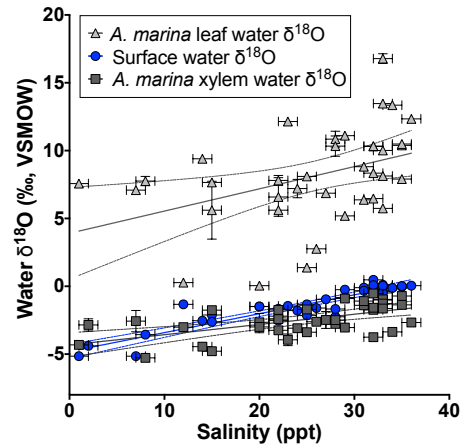

c)

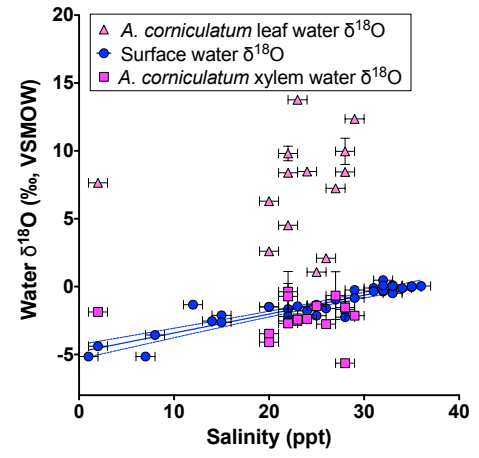

d)

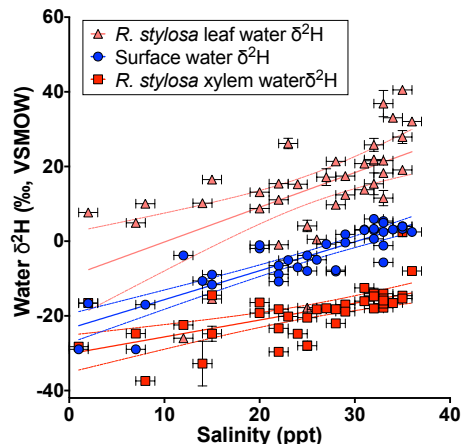

e)

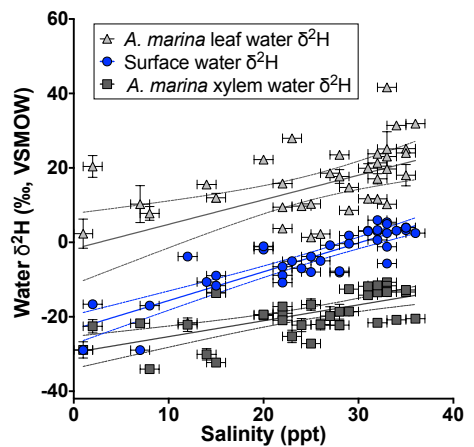

f)

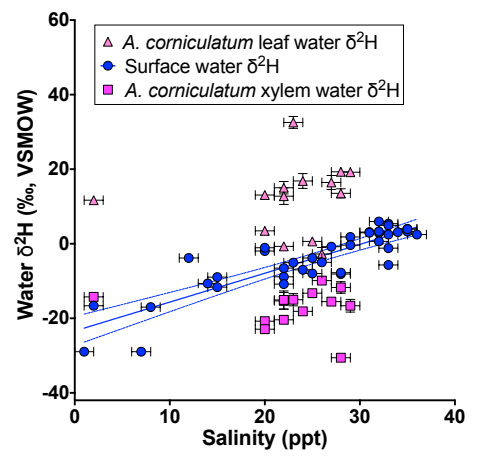

\begin{tabular}{|c|c|c|c|c|c|c|c|c|c|c|}
\hline \multicolumn{5}{|c|}{$\delta^{18} \mathrm{O}$} & & \multicolumn{5}{|c|}{$\delta^{2} \mathbf{H}$} \\
\hline $\mathbf{m}$ & b & $\mathbf{R}^{2}$ & p & $\mathbf{n}$ & Water & $\mathbf{m}$ & b & $\mathbf{R}^{2}$ & $\mathbf{p}$ & $\mathbf{n}$ \\
\hline $0.14 \pm 0.01$ & $4.8 \pm 0.3$ & 0.85 & $<0.0001$ & 39 & Surface (all panels) & $0.77 \pm 0.07$ & $-23 \pm 2$ & 0.76 & $<0.0001$ & 39 \\
\hline $0.08 \pm 0.02$ & $4.5 \pm 0.4$ & 0.40 & $<0.0001$ & 39 & R. stylosa xylem (panels a \& d) & $0.45 \pm 0.09$ & $-30 \pm 2$ & 0.39 & $<0.0001$ & 39 \\
\hline $0.22 \pm 0.07$ & $2 \pm 2$ & 0.25 & 0.002 & 36 & $R$. stylosa leaf (panels a \& d) & $0.9 \pm 0.2$ & $-9 \pm 6$ & 0.35 & 0.0001 & 36 \\
\hline $0.08 \pm 0.02$ & $4.3 \pm 0.4$ & 0.36 & $<0.0001$ & 37 & A. marina xylem (panels b \& e) & $0.43 \pm 0.08$ & $-29 \pm 2$ & 0.44 & $<0.0001$ & 37 \\
\hline $0.16 \pm 0.06$ & $4 \pm 2$ & 0.17 & 0.01 & 37 & A. marina leaf (panels b \& e) & $0.7 \pm 0.2$ & $-2 \pm 5$ & 0.28 & 0.0006 & 37 \\
\hline$-0.01 \pm 0.06$ & $2 \pm 1$ & 0.01 & 0.82 & 14 & A. cornic. xylem (panels c \& f) & $0.1 \pm 0.2$ & $-15 \pm 5$ & 0.01 & 0.79 & 14 \\
\hline $0.1 \pm 0.01$ & $6 \pm 4$ & 0.01 & 0.74 & 14 & A. cornic. leaf (panels c \& f) & $0.1 \pm 0.4$ & $9 \pm 10$ & 0.01 & 0.73 & 14 \\
\hline
\end{tabular}




\section{$864 \quad$ Figure 4}
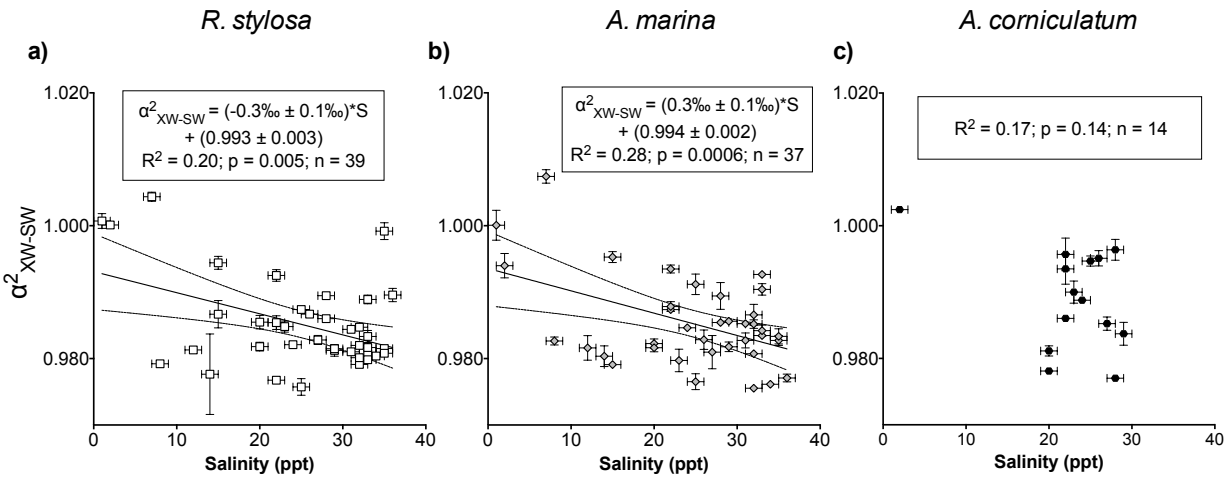

d)

e)

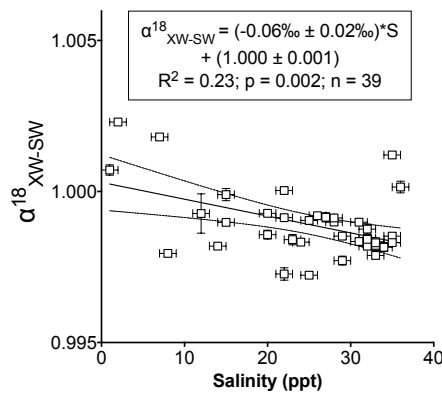

f)

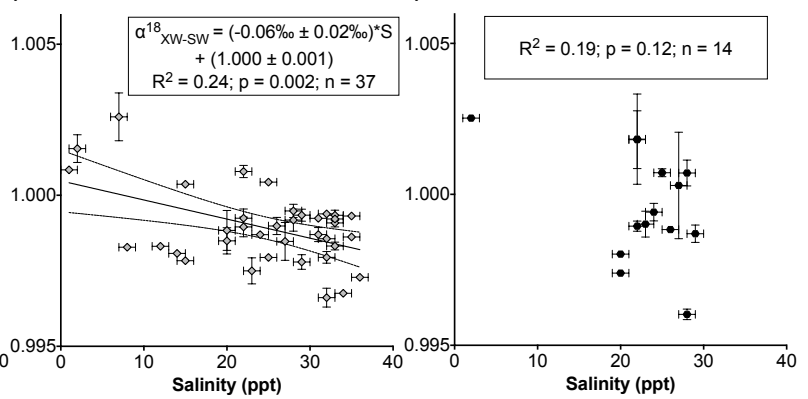




\section{$868 \quad$ Figure 5}
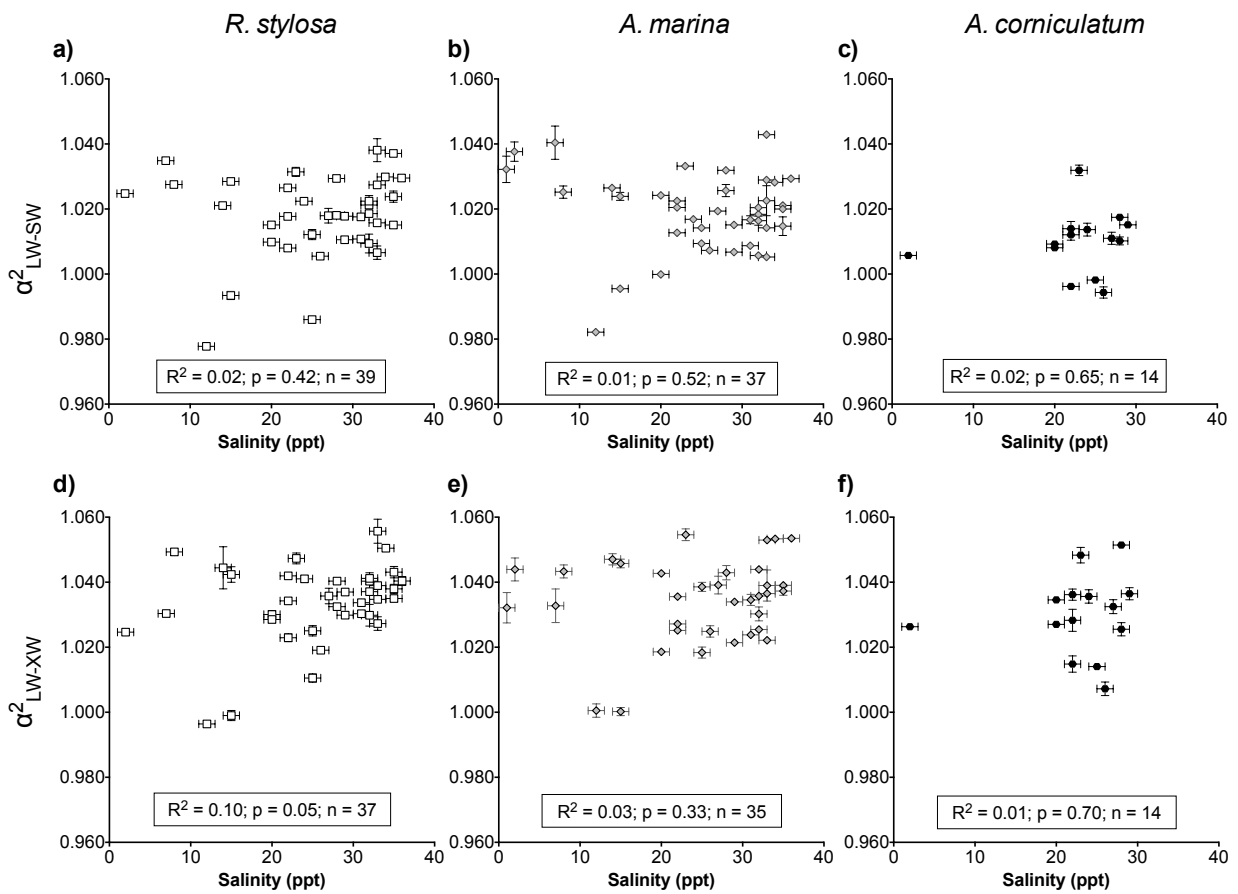

e)

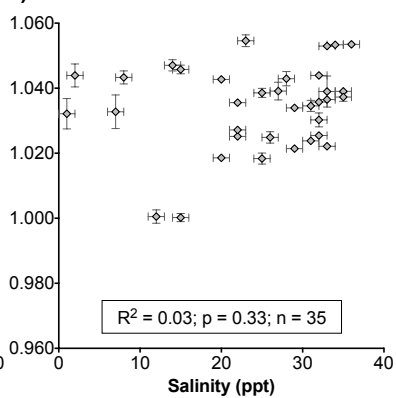

f)

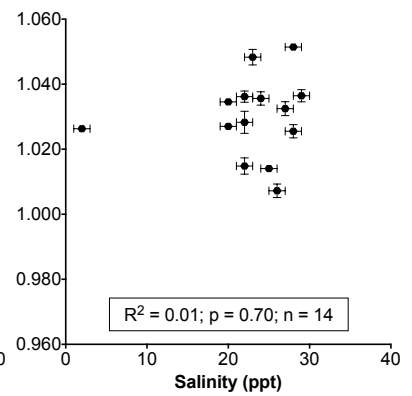




\section{$872 \quad$ Figure 6}
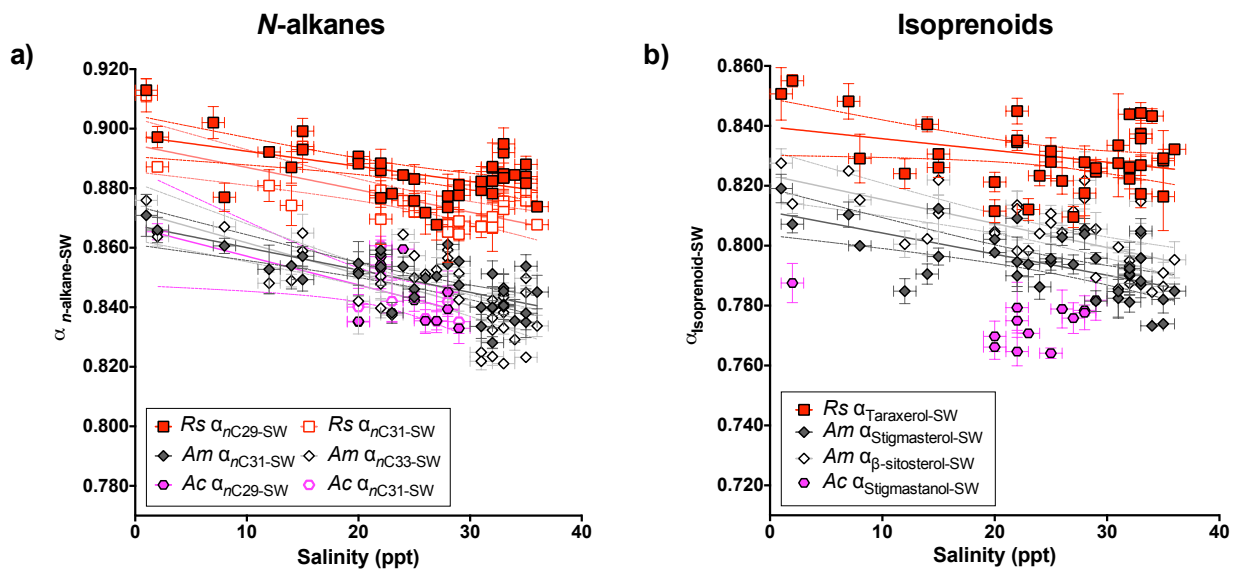

\begin{tabular}{|c|c|c|c|c|c|}
\hline $\boldsymbol{\alpha}_{\text {Lipid-SW }}$ & $\mathbf{m ~ ( \% )}$ & $\mathbf{b}$ & $\mathbf{R}^{\mathbf{2}}$ & $\mathbf{p}$ & $\mathbf{n}$ \\
\hline R. stylosa $n \mathrm{C}_{29}\left(\mathrm{Rs} \alpha_{n \mathrm{C} 29-\mathrm{SW}}\right)$ & $-0.5 \pm 0.1$ & $0.898 \pm 0.003$ & 0.30 & 0.003 & 39 \\
\hline R. stylosa $n \mathrm{C}_{31}\left(\mathrm{Rs} \alpha_{n \mathrm{C} 31-\mathrm{SW}}\right)$ & $-0.8 \pm 0.2$ & $0.895 \pm 0.004$ & 0.50 & 0.0001 & 24 \\
\hline A. marina $n \mathrm{C}_{31}\left(\mathrm{Am} \alpha_{n \mathrm{C} 31-\mathrm{SW}}\right)$ & $-0.8 \pm 0.1$ & $0.868 \pm 0.003$ & 0.52 & $<0.0001$ & 38 \\
\hline A. marina $n \mathrm{C}_{33}\left(\mathrm{Am} \alpha_{n \mathrm{C} 33-\mathrm{SW}}\right)$ & $-1.1 \pm 0.2$ & $0.872 \pm 0.005$ & 0.50 & $<0.0001$ & 38 \\
\hline A. corniculatum $n \mathrm{C}_{29}\left(\mathrm{Ac} \alpha_{n \mathrm{C} 29-\mathrm{SW}}\right)$ & $-1.0 \pm 0.4$ & $0.867 \pm 0.009$ & 0.35 & 0.03 & 14 \\
\hline A. corniculatum $n \mathrm{C}_{31}\left(\mathrm{Ac} \alpha_{n \mathrm{C} 31-\mathrm{SW}}\right)$ & $-0.9 \pm 0.7$ & $0.87 \pm 0.02$ & 0.17 & 0.21 & 11 \\
\hline R. stylosa taraxerol $\left(\mathrm{Rs} \alpha_{\text {Taraxerol-SW}}\right)$ & $-0.4 \pm 0.2$ & $0.840 \pm 0.005$ & 0.12 & 0.03 & 36 \\
\hline A. marina stigmasterol $\left(\mathrm{Am} \alpha_{\text {Stigmasterol-SW }}\right)$ & $-0.7 \pm 0.1$ & $0.811 \pm 0.004$ & 0.40 & $<0.0001$ & 37 \\
\hline A. marina $\beta$-sitosterol $\left(\mathrm{Am} \alpha_{\beta-\text {-sitosterol-SW }}\right)$ & $-0.8 \pm 0.1$ & $0.824 \pm 0.004$ & 0.44 & 0.0001 & 36 \\
\hline A. corniculatum stigmastanol $\left(\mathrm{Ac} \alpha_{\text {stigmastanol-SW }}\right)$ & $-0.3 \pm 0.3$ & $0.781 \pm 0.007$ & 0.07 & 0.39 & 13 \\
\hline
\end{tabular}

873

874 


\section{$876 \quad$ Figure 7}

a)

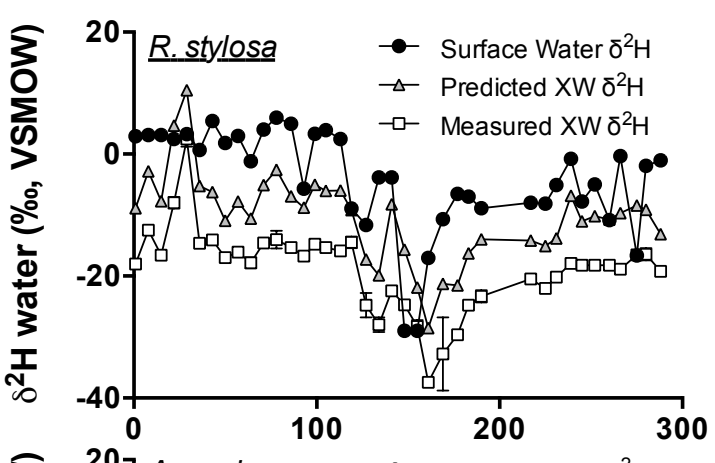

b)

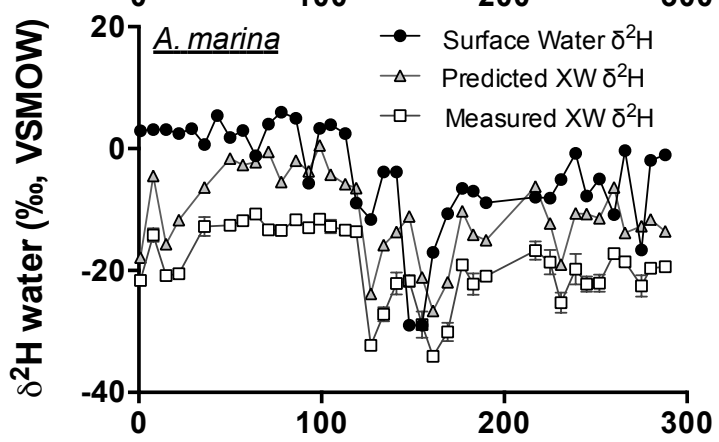

c) $\left.\lesseqgtr{ }^{20}\right]$ A. corniculatum $\bullet-$ Surface Water $\delta^{2} \mathrm{H}$

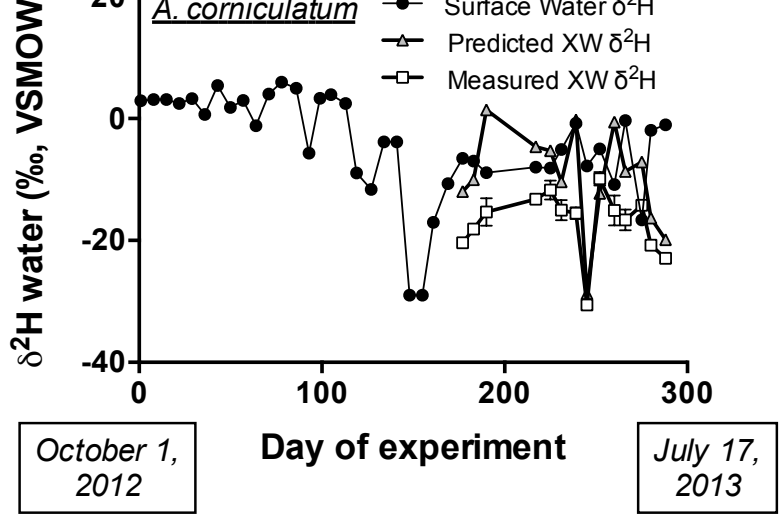

